\title{
Highly Stable Red-Light-Emitting Electrochemical Cells
}

\author{
Cathrin D. Ertl, ${ }^{1,}$ Cristina Momblona, ${ }^{1, \dagger}$ Antonio Pertegás, ${ }^{\dagger}$ José M. Junquera-Hernández, ${ }^{\dagger}$ \\ Maria-Grazia La-Placa, ${ }^{\dagger}$ Alessandro Prescimone,${ }^{\dagger}$ Enrique Ortí, ${ }^{\dagger}$ Catherine E. Housecroft, ${ }^{*}$ \\ Edwin C. Constable, ${ }^{\ddagger}$ and Henk J. Bolink ${ }^{*}, \dagger$ \\ ${ }_{\dagger}^{\dagger}$ Instituto de Ciencia Molecular, Universidad de Valencia, C/ Catedrático José Beltrán 2, ES- \\ 46980 Paterna (Valencia), Spain \\ ${ }^{*}$ Department of Chemistry, University of Basel, Spitalstrasse 51, CH-4056 Basel, Switzerland \\ 1) Contributed equally to this work. \\ *Email: catherine.housecroft@unibas.ch, henk.bolink@uv.es
}

\begin{abstract}
The synthesis and characterization of a series of new cyclometalated iridium(III) complexes $\left[\operatorname{Ir}(\mathrm{ppy})_{2}\left(\mathrm{~N}^{\wedge} \mathrm{N}\right)\right]\left[\mathrm{PF}_{6}\right]$ in which Hppy $=2$-phenylpyridine and $\mathrm{N}^{\wedge} \mathrm{N}$ is (pyridin-2yl)benzo $[d]$ thiazole (L1), 2-(4-(tert-butyl)pyridin-2-yl)benzo[d]thiazole $\quad(\mathbf{L 2}), \quad 2-(6-$ phenylpyridin-2-yl)benzo[d]thiazole $\quad(\mathbf{L 3}), \quad 2$-(4-(tert-butyl)-6-phenylpyridin-2yl)benzo $[d]$ thiazole $\quad(\mathbf{L} 4), \quad 2,6$-bis(benzo $[d]$ thiazol-2-yl)pyridine $\quad(\mathbf{L 5}), \quad 2$-(pyridin-2yl)benzo $[d]$ oxazole $(\mathbf{L 6})$ or 2,2'-dibenzo $[d]$ thiazole $(\mathbf{L} 7)$ are reported. The single crystal structures of $\left[\operatorname{Ir}(\mathrm{ppy})_{2}(\mathbf{L} \mathbf{1})\right]\left[\mathrm{PF}_{6}\right]^{1} 1.5 \mathrm{CH}_{2} \mathrm{Cl}_{2}$, $\left[\operatorname{Ir}(\mathrm{ppy})_{2}(\mathbf{L} \mathbf{6})\right]\left[\mathrm{PF}_{6}\right] \cdot \mathrm{CH}_{2} \mathrm{Cl}_{2}$ and $\left[\operatorname{Ir}(\mathrm{ppy})_{2}(\mathbf{L} 7)\right]\left[\mathrm{PF}_{6}\right]$ have been determined. The series of seven complexes are efficient red emitters and have been used in the active layers in light emitting electrochemical cells (LECs). The effects of modifications of the 2-(pyridin-2-yl)benzo[d]thiazole ligand on the photoluminescence and LEC performance have been examined. Extremely stable red-emitting LECs are obtained and when $\left[\operatorname{Ir}(\mathrm{ppy})_{2}(\mathbf{L} 1)\right]\left[\mathrm{PF}_{6}\right],\left[\operatorname{Ir}(\mathrm{ppy})_{2}(\mathbf{L 2})\right]\left[\mathrm{PF}_{6}\right]$ or $\left[\operatorname{Ir}(\mathrm{ppy})_{2}(\mathbf{L} \mathbf{3})\right]\left[\mathrm{PF}_{6}\right]$ are used in the active layer, device lifetimes $>1000,6000$ and 4000 hours, respectively, are observed
\end{abstract}

\section{INTRODUCTION}

Lighting is one of the most important needs for daily life. Light-emitting electrochemical cells (LECs) have great potential as light-emitting devices that have emerged over the last 20 years. ${ }^{1-11}$ LECs are simpler than organic light-emitting diodes (OLEDs), because they are typically based on a single layer architecture, whereas OLEDs employ a multilayer stack. ${ }^{12}$ The active layer of a LEC consists of an emitter containing ions, either using a polymeric material or an ionic transition-metal complex (iTMC), ${ }^{13-15}$ sandwiched between two air-stable electrodes. This allows for the preparation of novel form factors such as fibers, ${ }^{16}$ and on-chip designs. iTMCs, and particularly iridium-iTMCs, are the most explored type of electroluminescent 
material in LECs due their phosphorescence emission that allows to theoretically achieve $100 \%$ of luminescence conversion. ${ }^{17}$ The operation of LECs depends on the movement of ions, which can lead to a delay in turn-on of light emission after applying a bias. Additionally, the movement of ions eventually also leads to a reduction of luminance. If LECs are to be applied commercially, a combination of fast responses with efficient and stable devices must be accomplished. Since 2004, ${ }^{18}$ when Slinker et al. employed the first iridium-iTMC, many types of ligands and substituents have been studied, reporting lifetimes up to 3000 hours for orangeemitting LECs. ${ }^{19}$ We have shown that this objective is facilitated by operating the device under pulsed current. ${ }^{14}$

The stability of LECs, as for OLEDs, depends on the current applied through the device and decreases with increasing current density. This dependency is typically stronger in LECs because of the increase in ion separation leading to the growing of doped regions ${ }^{20}$ or to chemical degradation. ${ }^{21}$ Additionally, the efficiency typically decreases with increasing current densities, due to exciton-polaron and exciton-exciton quenching processes. Recently, reports were published showing that the charge carrier balance is improved by adding lithium salts to the light-emitting layer. ${ }^{22-24}$ Many different emission colors have been reported ranging from blue to deep red and even near infrared, yet few pure red-emitting LECs have been reported. ${ }^{25}$ This color is important in applications such as signage and automotive. Generally, pure-red LECs under DC operation mode exhibit lifetimes of a few hours. ${ }^{8,11,25,26}$ Tamayo et al. reported a

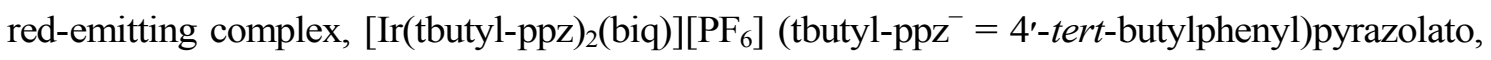
biq $=2,2^{\prime}$-biquinoline), that was used in LECs showing a luminance of $7500 \mathrm{~cd} \mathrm{~m}^{-2}$ (no lifetime data were presented). ${ }^{8}$ Zhang et al. also reported a red-LEC using the $\left[\operatorname{Ir}(\mathrm{ppy})_{2}(\right.$ pyoxd $\left.)\right]\left[\mathrm{PF}_{6}\right]$ complex ( ppy $^{-}=2$-phenylpyridinate, pyoxd $=2$-phenyl-5-(2-pyridyl)-1,3,4-oxadiazole) with an EQE of $9.51 \%{ }^{11}$ However, the lifetime of the device (time required to reach one-half of the maximum luminance, $t_{1 / 2}$ ) under constant-voltage of $5 \mathrm{~V}$ was $490 \mathrm{~min}$. Hu et al. introduced in a host-guest configuration an $\mathrm{N}^{\wedge} \mathrm{N}$ ancillary benzoimidazole ligand in $\left[\operatorname{Ir}(\mathrm{ppy})_{2}(\mathrm{qIbi})\right]\left[\mathrm{PF}_{6}\right](\mathrm{qIbi}$ $=2-\left(1-\right.$ phenyl-1H-benzoimidazol-2-yl)quinoline) producing a LEC with a deep red emission. ${ }^{27}$

In cyclometalated $\left[\operatorname{Ir}\left(\mathrm{C}^{\wedge} \mathrm{N}\right)_{2}\left(\mathrm{~N}^{\wedge} \mathrm{N}\right)\right]^{+}$complexes, the benzothiazole moiety has previously been used as part of the cyclometalating $\mathrm{C}^{\wedge} \mathrm{N}$ ligand, for example as 2phenylbenzo $[d]$ thiazole. ${ }^{28-30}$ Although complexes of other metal ions coordinated by 2-(pyridin2 -yl)benzo[d]thiazole (btzpy) have been investigated, ${ }^{31,32}$ there is only one example of an $\left[\operatorname{Ir}\left(\mathrm{C}^{\wedge} \mathrm{N}\right)_{2}\left(\mathrm{~N}^{\wedge} \mathrm{N}\right)\right]^{+}$complex incorporating a related $\mathrm{N}^{\wedge} \mathrm{N}$ domain $\left(\mathrm{N}^{\wedge} \mathrm{N}=2\right.$-(pyridin-2-yl)-4,5dihydrothiazole); in this example, the focus of attention was on the use of the iridium(III) complex as a photosensitizer for catalytic water reduction. ${ }^{33}$

Here, we report a series of LECs using the ionic iridium(III) complex $\left[\operatorname{Ir}(\mathrm{ppy})_{2}(\mathrm{btzpy})\right]\left[\mathrm{PF}_{6}\right]$ having ppy ${ }^{-}$as the cyclometalating ligand and btzpy as the $\mathrm{N}^{\wedge} \mathrm{N}$ ancillary 
ligand. The incorporation of substituents, replacement for other ligands, and the role of the heteroatom in the benzothiazole unit are analyzed. All LECs exhibit deep red to infrared electroluminescence. Long lifetimes even when driven at high current densities are obtained.

\section{EXPERIMENTAL SECTION}

Synthesis and compound characterization: Starting materials were obtained in reagent grade and used as received. Dry solvents were purchased from Sigma-Aldrich or Acros Organics and used for reactions carried out under inert atmosphere. For all other reactions, solvents used were of reagent grade or distilled. HPLC grade solvents were used for analyses. Column chromatography was performed using Fluka silica gel $60(0.040-0.063 \mathrm{~mm})$.

1D and 2D NMR spectra were measured on a Bruker Avance III-500 (500 MHz) spectrometer. Chemical shifts are referenced to residual solvent peaks with $\delta(\mathrm{TMS})=0 \mathrm{ppm}$. Electrospray ionization mass spectra were recorded on a Bruker esquire $3000^{\text {plus }}$ spectrometer. LC-ESI mass spectra were obtained on a combination of Shimadzu (LC) and Bruker AmaZon X instruments. Elemental analysis was performed on an Elementar Vario Micro Cube instrument and high resolution ESI mass spectra on a Bruker maXis 4G QTOF spectrometer. FT-IR spectra were recorded on a Perkin Elmer Spectrum Two UATR instrument. Absorption spectra were measured on an Agilent 8453 spectrophotometer and solution emission spectra on a Shimadzu 5301PC spectrofluorophotometer. Solution and powder photoluminescence quantum yields were recorded on a Hamamatsu absolute PL quantum yield spectrometer C11347 Quantaurus QY. Emission spectra of powder samples as well as solution and powder excited-state lifetime measurements were carried out on a Hamamatsu Compact Fluorescence lifetime spectrometer C11367 Quantaurus Tau. Electrochemical measurements were performed using cyclic and square-wave voltammetry on a $\mathrm{CH}$ Instruments $900 \mathrm{~B}$ potentiostat with both glassy carbon and platinum working and platinum auxiliary electrodes; a silver wire was used as a pseudoreference electrode. Dry, purified $\mathrm{CH}_{2} \mathrm{Cl}_{2}$ was used as solvent and $0.1 \mathrm{M} \mathrm{TBAPF}_{6}$ as supporting electrolyte. Ferrocene as internal reference was added at the end of each experiment.

Crystallography: Single crystal structure determination was carried out on a Bruker APEXII diffractometer. Data reduction, solution and refinement used the programs APEX ${ }^{34}$ and SHELXL97. ${ }^{35}$ Structure analysis was done using Mercury v. 3.6. ${ }^{36}$

Photoluminescence characterization: The samples for thin-film photoluminescence measurements were done with the same composition and thickness than the emissive layer of LECs. Each complex was mixed with the ionic liquid (IL) 1-butyl-3-methylimidazolium hexafluoridophosphate $\left([\mathrm{Bmim}]\left[\mathrm{PF}_{6}\right]\right)$ in a 4-to-1 molar ratio. A $100 \mathrm{~nm}$ thick film was 
deposited from a $20 \mathrm{mg} \mathrm{mL}^{-1}$ solution of complexes $\mathbf{1 , 5}$, and $\mathbf{6}$ in acetonitrile, complexes $\mathbf{2 , 3}$, and 4 in dichloromethane, and complex 7 in methyl ethyl ketone:anisol 3:2, respectively. Prior to deposition, all solutions were filtered with a $0.22 \mu \mathrm{m}$ pore size filter and spin-coated at 1000 rpm for $30 \mathrm{~s}$ in air onto cleaned quartz substrates. As the films obtained from the filtered solutions of complexes $\mathbf{2}$ and $\mathbf{4}$ in the LEC layout were inhomogeneous, a small amount of $2 \mathrm{wt}-$ $\%$ of PMMA was added to improve the homogeneity of the layer.

The thin-film photoluminescence spectra and quantum yields were measured in air with a Hamamatsu C9920-02 Absolute PL Quantum Yield Measurement System.

Computational details: Density functional calculations (DFT) were carried out with the D.01 revision of the Gaussian 09 program package ${ }^{37}$ using Becke's three-parameter B3LYP exchange-correlation functional ${ }^{38,39}$ together with the $6-31 \mathrm{G}^{* *}$ basis set for $\mathrm{C}, \mathrm{H}, \mathrm{N}, \mathrm{S}$, and $\mathrm{O},{ }^{40}$ and the "double- $\zeta$ " quality LANL2DZ basis set for the Ir element. ${ }^{41}$ An effective core potential (ECP) replaces the inner core electrons of Ir leaving the outer core $\left[(5 s)^{2}(5 p)^{6}\right]$ electrons and the $(5 \mathrm{~d})^{6}$ valence electrons of $\operatorname{Ir}(\mathrm{III})$. The geometries of the singlet ground state $\left(\mathrm{S}_{0}\right)$ and of the lowest-energy triplet state $\left(\mathrm{T}_{1}\right)$ were fully optimized without imposing any symmetry restriction. Phosphorescence emission energies were estimated as the vertical difference between the energy of the minimum of the lowest-energy triplet state and the energy of $S_{0}$ at the $T_{1}$ optimized geometry. The calculation of the energy of $\mathrm{S}_{0}$ at the $\mathrm{T}_{1}$ geometry was performed as an equilibrium single-point calculation with respect to the solvent reaction field/solute electronic density polarization process. All the calculations were performed in the presence of the solvent (dichloromethane). Solvent effects were considered within the self-consistent reaction field (SCRF) theory using the polarized continuum model (PCM) approach. ${ }^{42-44}$ Time-dependent DFT (TD-DFT) $)^{45-47}$ calculations of the lowest lying 6 triplets of all systems, and the lowest 40 singlets of 1 and 7, were performed in the presence of the solvent at the minimum-energy geometry optimized for the ground state.

LEC fabrication: All materials were used as received. Poly(3,4ethylenedioxythiophene):polystyrene sulfonate (PEDOT:PSS Clevios P VP Al 4083) was purchased from Heraeus. The ionic liquid (IL) 1-butyl-3-methylimidazolium hexafluoridophosphate $\left([\mathrm{Bmim}]\left[\mathrm{PF}_{6}\right]\right)$ and the poly(methyl metacrylate) (PMMA, Mw = $120000 \mathrm{~g} \mathrm{~mol}^{-1}$ ) were purchased from Sigma Aldrich. The solvents acetonitrile, dichloromethane, methyl ethyl ketone, and anisol were purchased from Sigma Aldrich. The photolithography-patterned indium tin oxide (ITO) glass substrates were purchased from Naranjo Substrates (www.naranjosubstrates.com).

LECs were prepared as follows. The substrates were subsequently cleaned with soap, deionized water, and isopropanol in an ultrasonic bath for 5 minutes each, followed by 20 
minutes of UV-ozone treatment. Onto the clean ITO substrates, an $80 \mathrm{~nm}$ thick film of PEDOT:PSS was spin-coated at $1000 \mathrm{rpm}$ for $60 \mathrm{~s}$. The PEDOT:PSS was added from a syringe and filtered with a $0.45 \mu \mathrm{m}$ pore size filter. The PEDOT:PSS layer was dried at $150{ }^{\circ} \mathrm{C}$ for 15 minutes. On top of it, a $100 \mathrm{~nm}$ thick film of the emissive layer was deposited in the same conditions that were described for thin-film photoluminescence samples. In brief, filtered solutions of complex:IL in a 4-to-1 molar ratio were spin-coated in air at $1000 \mathrm{rpm}$ for $30 \mathrm{~s}$ and transferred to a glove box (MBraun, $\mathrm{O}_{2}<0.1 \mathrm{ppm}, \mathrm{H}_{2} \mathrm{O}<0.1 \mathrm{ppm}$ ) for annealing at $100{ }^{\circ} \mathrm{C}$ for 1 hour. Finally, a $70 \mathrm{~nm}$ thick film of aluminum was deposited as top electrode contact using a shadow mask. The active area in all devices is $0.634 \mathrm{~cm}^{2}$.

LEC characterization: LECs using complexes 1-6 were tested by applying pulsed current and by monitoring the voltage and the luminance with a True Colour Sensor (MTCSiCT Sensor, MAZeT GimbH) using a Lifetime Test System (Botest OLT OLED Lifetime-Test System, Botest System $\mathrm{GmbH}$ ). The pulsed current consisted of a block wave at $1 \mathrm{kHz}$ frequency with a duty cycle of 50\%. LEC with complex 7 was tested by applying pulsed current with the Lifetime Test System and the irradiance was monitored with a sensitive Si-photodiode coupled to an integrating sphere. The peak current density of the pulse was $200 \mathrm{~A} \mathrm{~m}^{-2}$ and the average current density was $100 \mathrm{~A} \mathrm{~m}^{-2}$ for LECs 1-6. For further understanding of the stability of LEC $\mathbf{1}$, this device was driven at average current densities of 300,700,1250, and $1500 \mathrm{~A} \mathrm{~m}^{-2}$. Electroluminescence spectra were recorded using an Avantes fibre optics photo-spectrometer. All devices were tested without encapsulation and were characterized inside the glove-box at room temperature. For each device configuration, we evaluated 8 cells to ensure meaningful statistics.

\section{RESULTS AND DISCUSSION}

\section{Ligand synthesis}

The chemical structures of ancillary ligands L1-L7 used in this series of complexes are shown in Scheme 1 and the syntheses are detailed in the Supporting Information. 2-(Pyridin-2yl)benzo[ $[d]$ thiazole (L1), 2-(4-(tert-butyl)pyridin-2-yl)benzo[ $d]$ thiazole (L2), and 2-(pyridin-2yl)benzo $[d]$ oxazole (L6) were prepared by adaptation of a copper-catalyzed coupling reaction described in the literature. ${ }^{48} \quad 2,6-\operatorname{Bis}\left(\right.$ benzo $[d]$ thiazol-2-yl)pyridine $(\mathbf{L 5})^{49}$ and 2,2'bibenzo $[d]$ thiazole $(\mathbf{L} 7)^{50}$ were synthesized following reported literature procedures by a condensation reaction of 2-aminothiophenol with 2,6-pyridinedicarboxaldehyde or oxalic acid, respectively. The synthesis of 2-(6-phenylpyridin-2-yl)benzo[d]thiazole (L3) and 2-(4-(tertbutyl)-6-phenylpyridin-2-yl)benzo[d]thiazole (L4) has not yet been reported. Bromination of 2- 
phenylpyridine and 4-(tert-butyl)-2-phenylpyridine with $n$-BuLi/LiDMAE and $\mathrm{CBr}_{4}{ }^{51}$ gave 2bromo-6-phenylpyridine and 2-bromo-4-(tert-butyl)-6-phenylpyridine, which were then used in $\mathrm{Cu}(\mathrm{I})$-catalyzed coupling reactions with benzothiazole ${ }^{48}$ to yield the desired products $\mathbf{L 3}$ and $\mathbf{L} \mathbf{4}$ in moderate yields. Ligands $\mathbf{L 3}$ and $\mathbf{L} \mathbf{4}$ were characterized by 1D and 2D NMR spectroscopy, LC-ESI mass spectrometry, IR spectroscopy, and elemental analysis. In the mass spectra, the base peaks at $m / z 289.0$ (for L3) and 345.1 (for L4) correspond to the protonated ligands $[M+\mathrm{H}]^{+}$.
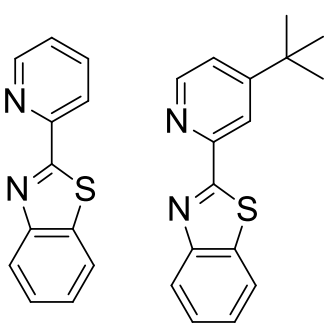

L2

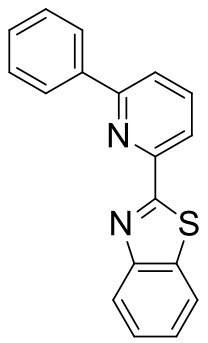

L3

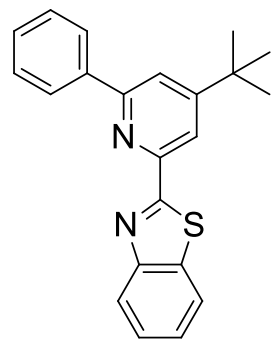

L4

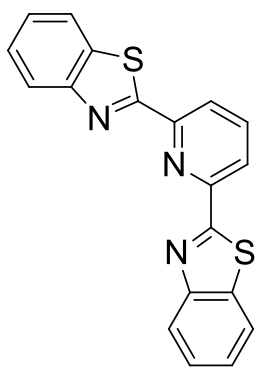

L5

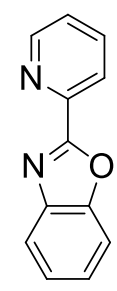

L6

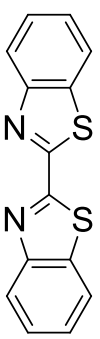

L7

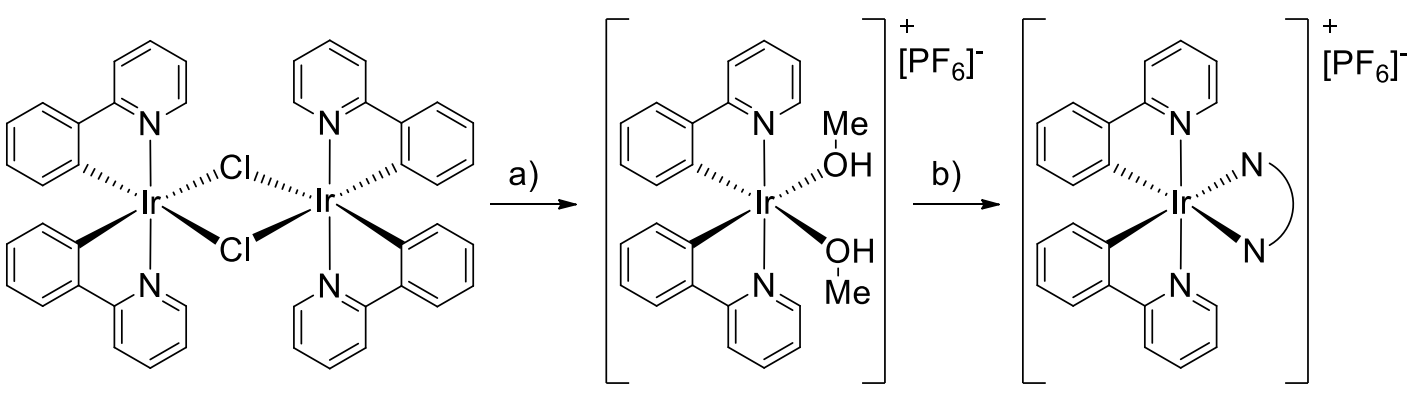

1 - $80.6 \%$

2 - $70.9 \%$

$3-87.5 \%$

$4-85.8 \%$

$5-49.0 \%$

$6-78.6 \%$

$7-81.9 \%$

Scheme 1. Synthesis of iridium(III) complexes 1-7. Reaction conditions: a) $\mathrm{AgPF}_{6}, \mathrm{MeOH}$ room temperature, 2-3.5 h; b) $\mathrm{N}^{\wedge} \mathrm{N}(\mathbf{L 1}-\mathbf{L} 7), \mathrm{MeOH}$, room temperature, overnight. Reported yields (over two steps) are calculated based on the dimer starting materials.

\section{Synthesis of $\left[\operatorname{Ir}\left(C^{\wedge} N\right)_{2}\left(N^{\wedge} N\right)\right]\left[P_{6}\right]$ complexes}

Cationic iridium complexes of the type $\left[\operatorname{Ir}\left(\mathrm{C}^{\wedge} \mathrm{N}\right)_{2}\left(\mathrm{~N}^{\wedge} \mathrm{N}\right)\right]^{+}$are typically synthesized by cleavage of the $\left[\operatorname{Ir}(\mathrm{ppy})_{2} \mathrm{Cl}\right]_{2}$ dimer with the desired $\mathrm{N}^{\wedge} \mathrm{N}$ ligand in $\mathrm{MeOH}$ or $\mathrm{CH}_{2} \mathrm{Cl}_{2} / \mathrm{MeOH}^{52-}$ ${ }^{54}$ Using this method, however, traces of chloride ions can be carried through to the final product, despite using an excess of $\mathrm{NH}_{4} \mathrm{PF}_{6}$ for ion metathesis. We have recently shown that these chloride impurities are detrimental to device performance. ${ }^{55}$ Therefore, the complexes in this series were prepared via an intermediate solvento complex, formed by the reaction of the iridium dimer with $\mathrm{AgPF}_{6}$ in $\mathrm{MeOH}$ (Scheme 1). During the reaction, $\mathrm{AgCl}$ precipitates and is removed by filtration through Celite ${ }^{\circledR}$. The filtrate is concentrated and the solvento intermediate is used immediately without purification or characterization for subsequent transformations. As shown in a series of stable orange emitters, the purity obtained by this synthetic route can lead 
to excellent LEC performance, decreasing the risk of chloride ion impurities in the final complexes. ${ }^{56}$ In Scheme 1, the synthetic strategy to complexes 1-7 is shown. Reaction of the $\left[\operatorname{Ir}(\text { ppy })_{2}(\mathrm{MeOH})_{2}\right]\left[\mathrm{PF}_{6}\right]$ intermediate with the corresponding $\mathrm{N}^{\wedge} \mathrm{N}$ ligands $\mathbf{L 1}-\mathbf{L} 7$ in $\mathrm{MeOH}$ at room temperature gave the desired iridium complexes in moderate to good yields based on the iridium dimer starting material. All complexes in this series were fully characterized by 1D and 2D NMR spectroscopy, IR spectroscopy, ESI-MS, and elemental analysis. The base peaks in the ESI mass spectra correspond to the $\left[M-\mathrm{PF}_{6}\right]^{+}$cations.

\section{Crystal structures}

Single crystals of $1 \cdot 1.5 \mathrm{CH}_{2} \mathrm{Cl}_{2}, \mathbf{6} \cdot \mathrm{CH}_{2} \mathrm{Cl}_{2}$, and 7 were grown by layering $\mathrm{CH}_{2} \mathrm{Cl}_{2}$ solutions of the complexes with $\mathrm{Et}_{2} \mathrm{O}$. Structures of the complex cations are shown in Figures 1 to 3, confirming that coordination occurs through the nitrogen atom(s) of the benzothiazole/benzoxazole unit(s) in all three complexes. $\mathbf{1} \cdot 1.5 \mathrm{CH}_{2} \mathrm{Cl}_{2}$ and $\mathbf{6} \cdot \mathrm{CH}_{2} \mathrm{Cl}_{2}$ crystallize in the monoclinic space groups $P 2_{1} / c$ and $P 2_{1} / n$, respectively, whereas 7 crystallizes in the orthorhombic space group $F d d 2 . \mathrm{CH}_{2} \mathrm{Cl}_{2}$ solvent molecules are heavily disordered in $\mathbf{1} \cdot 1.5 \mathrm{CH}_{2} \mathrm{Cl}_{2}$ and have been removed using the SQUEEZE ${ }^{57}$ method. In $\mathbf{6} \cdot \mathrm{CH}_{2} \mathrm{Cl}_{2}$, the $\mathrm{CH}_{2} \mathrm{Cl}_{2}$ solvent molecule is ordered. The asymmetric unit of 7 contains half a cation and half an anion; in each case, the second half is generated by a $C_{2}$ rotation axis which is parallel to the $c$ axis of the unit cell and runs through the iridium or the phosphorus center, respectively.

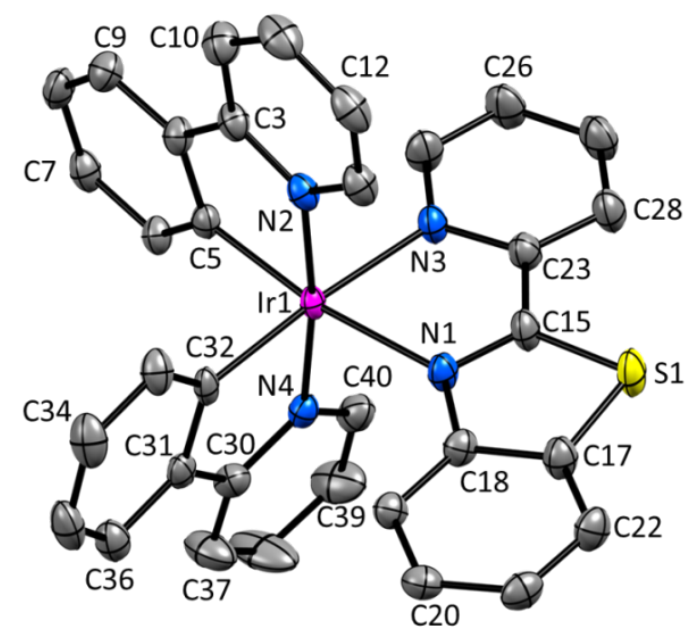

Figure 1. Structure of the $\Lambda$-[ $\left.\operatorname{Ir}(\mathrm{ppy})_{2}(\mathbf{L} \mathbf{1})\right]^{+}$cation in $\mathbf{1} \cdot 1.5 \mathrm{CH}_{2} \mathrm{Cl}_{2}$. $\mathrm{H}$ atoms omitted for clarity and ellipsoids plotted at 50\% probability level. Selected bond parameters: Ir1-N1 $=2.172(2)$, Ir1-N2 = 2.050(2), Ir1-N3 = 2.143(2), Ir1-N4 = 2.041(2), Ir1-C5 = 2.007(3), Ir1-C32 = 2.014(3), $\mathrm{S} 1-\mathrm{C} 15=1.731(3), \mathrm{S} 1-\mathrm{C} 17=1.742(3) \AA \AA$; N1-Ir1-N3 = 76.15(9), N2-Ir1-C5 = 80.63(10), N4-Ir1-C32 = 80.65(10), N1-Ir1-C5 = 171.48(9), N2-Ir1-N4 = 172.68(9), N3-Ir1$\mathrm{C} 32=175.40(10), \mathrm{C} 15-\mathrm{S} 1-\mathrm{C} 17=88.97(14)^{\circ}$. 
For $\mathbf{1} \cdot 1.5 \mathrm{CH}_{2} \mathrm{Cl}_{2}$ and $\mathbf{6} \cdot \mathrm{CH}_{2} \mathrm{Cl}_{2}$, the phenylpyridine ligand, of which the coordinating $\mathrm{C}$ atom is trans to the benzothiazole/benzoxazole unit, is nearly planar (angles between the ring planes are 3.3 and $2.7^{\circ}$, respectively). The other ppy cyclometallating ligand (coordinating carbon trans to the pyridine ring of the ancillary ligand) shows deviation from planarity, with angles between the ring planes of 8.2 and $10.9^{\circ}$, respectively. Whereas the $\mathbf{L 1}$ ancillary ligand in $\mathbf{1} \cdot 1.5 \mathrm{CH}_{2} \mathrm{Cl}_{2}$ is distorted from planarity (angle between the ring planes $=8.2^{\circ}$ ), ligand $\mathbf{L 6}$ in $\mathbf{6} \cdot \mathrm{CH}_{2} \mathrm{Cl}_{2}$ does not exhibit the same behavior (angle between the ring planes $=2.2^{\circ}$ ). In 7, both the ppy ${ }^{-}$and the $\mathbf{L} 7$ ligands are twisted so that the angles between the ring planes amount to 7.1 and $7.5^{\circ}$, respectively.

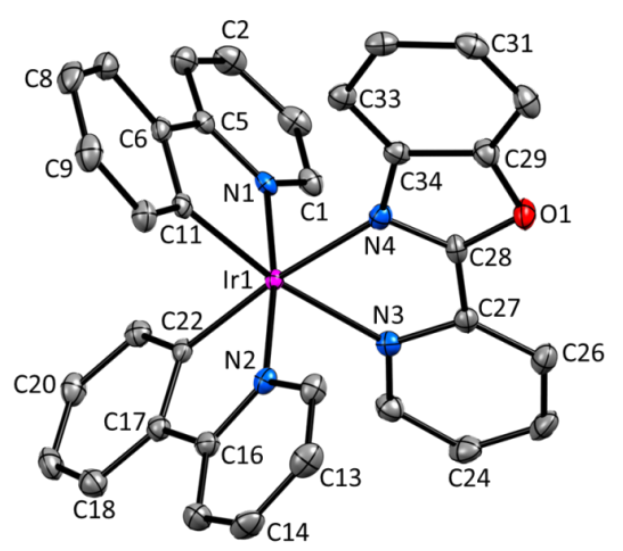

Figure 2. Structure of the $\Delta$-[Ir(ppy $\left.)_{2}(\mathbf{L 6})\right]^{+}$cation in $\mathbf{6} \cdot \mathrm{CH}_{2} \mathrm{Cl}_{2}$. $\mathrm{H}$ atoms omitted for clarity and ellipsoids plotted at 50\% probability level. Selected bond parameters: $\operatorname{Ir} 1-\mathrm{N} 1=2.044(2)$, Ir1$\mathrm{N} 2=2.055(2), \operatorname{Ir} 1-\mathrm{N} 3=2.173(2), \operatorname{Ir} 1-\mathrm{N} 4=2.140(2), \operatorname{Ir} 1-\mathrm{C} 11=2.009(3), \operatorname{Ir} 1-\mathrm{C} 22=2.008(3)$, $\mathrm{O} 1-\mathrm{C} 28=1.355(4), \mathrm{O} 1-\mathrm{C} 29=1.394(4) \AA ̊$; N1-Ir1-C11 = 80.60(11), N2-Ir1-C22 = 80.60(11), N3-Ir1-N4 = 76.33(9), N1-Ir1-N2 = 172.13(9), N3-Ir1-C11 = 170.59(10), N4-Ir1-C22 = 173.90(10), $\mathrm{C} 28-\mathrm{O} 1-\mathrm{C} 29=103.9(2)^{\circ}$.

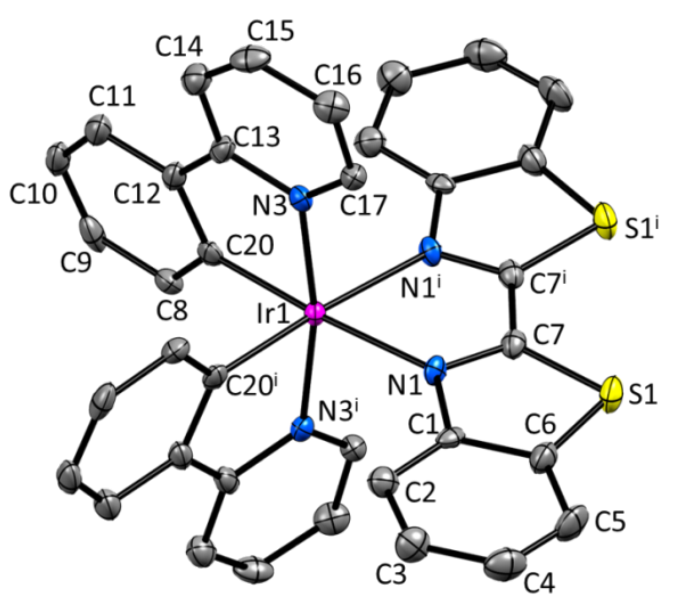


Figure 3. Structure of the $\Lambda$-[Ir(ppy $\left.)_{2}(\mathbf{L} 7)\right]^{+}$cation in 7 . $\mathrm{H}$ atoms omitted and ellipsoids plotted at $50 \%$ probability level. Symmetry code: $i=-x+1 / 2,-y+1 / 2, z+1$. Selected bond parameters: Ir $1-$ $\mathrm{N} 1=2.176(3), \operatorname{Ir} 1-\mathrm{N} 3=2.048(2), \operatorname{Ir} 1-\mathrm{C} 20=2.004(3), \mathrm{S} 1-\mathrm{C} 6=1.730(4), \mathrm{S} 1-\mathrm{C} 7=1.718(3) \AA ;$ $\mathrm{N} 1-\operatorname{Ir} 1-\mathrm{N} 1^{\mathrm{i}}=75.58(14), \mathrm{N} 3-\operatorname{Ir} 1-\mathrm{C} 20=80.75(12), \mathrm{N} 1-\operatorname{Ir} 1-\mathrm{C} 20=175.83(13), \mathrm{N} 3-\operatorname{Ir} 1-\mathrm{N} 3^{\mathrm{i}}=$ $168.96(15), \mathrm{C} 6-\mathrm{S} 1-\mathrm{C} 7=88.77(16)^{\circ}$.

\section{Electrochemical properties}

Electrochemical data gained from cyclic voltammetry measurements in $\mathrm{CH}_{2} \mathrm{Cl}_{2}$ solution are summarized in Table 1; cyclic voltammograms are depicted in Figure S1. Reduction potentials are similar for complexes 1-4 and $\mathbf{6}(-1.55$ to $-1.62 \mathrm{~V})$, indicating that reduction takes place mainly on the benzothiazole unit of the ancillary ligand and replacing benzothiazole by benzoxazole does not significantly influence the reduction potential. Both $\mathbf{5}$ and $\mathbf{7}$ are more readily reduced than complex $\mathbf{1}$, with $E_{1 / 2}^{\text {red }}$ shifted by 0.08 and $0.28 \mathrm{~V}$, respectively. The introduction of a second benzothiazole moiety therefore has a pronounced stabilization effect on the LUMO, especially in 7, where the two benzothiazoles are directly linked. A second reduction peak is observed for both complexes, which is not seen for the remaining five compounds within the accessible solvent window. Oxidation potentials are in a close range $(+0.86$ to $+1.01 \mathrm{~V})$, as expected for $\left[\operatorname{Ir}(\mathrm{ppy})_{2}\left(\mathrm{~N}^{\wedge} \mathrm{N}\right)\right]\left[\mathrm{PF}_{6}\right]$ complexes in which the HOMO is located on the iridium center and the cyclometalating ligand. For compound 7, oxidation is shifted to higher potential, which can be explained by the extremely electron-deficient nature of ligand $\mathbf{L 7}$, making oxidation of the iridium center more difficult. The opposite trend is seen in $\mathbf{3}$ and 4 , where the introduction of a phenyl group on the ancillary ligand facilitates oxidation. For complex 5, two irreversible oxidation waves are observed, whereas all other complexes exhibit only one reversible to quasi-reversible oxidation.

Table 1. Electrochemical data of complexes 1-7 in de-aerated $\mathrm{CH}_{2} \mathrm{Cl}_{2}$ solutions and referenced to $\mathrm{Fc} / \mathrm{Fc}^{+}$(see also Figure $\mathrm{S} 1$ ). ${ }^{a}$

\begin{tabular}{|c|c|c|c|}
\hline Complex & $\begin{array}{c}\mathrm{E}_{1 / 2}^{\mathrm{ox}}[\mathrm{V}] \\
\left(E_{p a}-E_{p c}[\mathrm{mV}]\right)\end{array}$ & $\begin{array}{c}\mathrm{E}_{1 / 2}^{\mathrm{red}}[\mathrm{V}] \\
\left(E_{p c}-E_{p a}[\mathrm{mV}]\right)\end{array}$ & $\Delta E_{1 / 2}[\mathrm{~V}]$ \\
\hline $\mathbf{1}$ & $+0.94(92)$ & $-1.55(83)$ & 2.49 \\
\hline $\mathbf{2}$ & $+0.92(95)$ & $-1.59(89)$ & 2.51 \\
\hline $\mathbf{3}$ & $+0.86^{\mathrm{qr}}(126)$ & $-1.57(95)$ & 2.43 \\
\hline $\mathbf{4}$ & $+0.87^{\mathrm{qr}}(151)$ & $-1.62(89)$ & 2.49 \\
\hline $\mathbf{5}$ & $+0.99^{\mathrm{ir}}$, & $-1.47(86)$, & 2.46 \\
$+1.17^{\mathrm{ir}}$ & $-2.30^{\mathrm{ir}}$ & 2.53 \\
\hline $\mathbf{6}$ & $+0.92^{\mathrm{qr}}(114)$ & $-1.61(104)$ & 2.28 \\
\hline $\mathbf{7}$ & $+1.01^{\mathrm{qr}}(144)$ & $-1.27^{\mathrm{qr}}(123)$, & $2.03^{\mathrm{qr}}(140)$ \\
\hline
\end{tabular}


${ }^{a}$ Measured using Pt working and counter electrodes, an Ag pseudo-reference electrode, and $0.1 \mathrm{M} \mathrm{TBAPF}_{6}$ as supporting electrolyte at a scan rate of $0.1 \mathrm{~V} \mathrm{~s}^{-1} . \mathrm{ir}=$ irreversible, $\mathrm{qr}=$ quasireversible.

\section{Photophysical properties}

$\mathrm{UV}$-Vis absorption spectra in $\mathrm{CH}_{2} \mathrm{Cl}_{2}$ solution are shown in Figure 4. All complexes show intense absorption bands in the UV with maxima in the range $254-314 \mathrm{~nm}$, which are ascribed to spin-allowed $\pi \rightarrow \pi^{*}$ transitions of the ligands. Lower energy bands between 350 and $450 \mathrm{~nm}$ correspond to spin-allowed metal-to-ligand $\left({ }^{1} \mathrm{MLCT}\right)$ and ligand-to-ligand charge transfer ( ${ }^{1}$ LLCT) excitations, whereas the low intensity tails above $450 \mathrm{~nm}$ arise from spin-forbidden ${ }^{3} \mathrm{MLCT},{ }^{3} \mathrm{LLCT}$, and ligand-centered $\left({ }^{3} \mathrm{LC}\right)$ transitions. ${ }^{14}$ With the exception of 7 , the UV-Vis absorption spectra of all complexes in this series are similar. Compound 7 exhibits more intense absorption bands at wavelengths higher than $360 \mathrm{~nm}$ compared to the other complexes, with considerably stronger absorption bands extending into the visible region (around $450 \mathrm{~nm}$ ). This feature is attributed to the ancillary ligand (L7).

Table 2. Photophysical properties of complexes 1-7 (see also Table S1).

\begin{tabular}{|c|c|c|c|c|c|c|c|c|}
\hline \multirow{2}{*}{ Complex } & \multicolumn{3}{|c|}{ Solution $^{a}$} & \multicolumn{3}{c|}{ Powder } & \multicolumn{2}{c|}{ Film $^{f}$} \\
\cline { 2 - 9 } & $\begin{array}{c}\lambda_{e m}^{\max } \\
{[\mathbf{n m}]^{b}}\end{array}$ & $\begin{array}{c}\boldsymbol{\tau}_{\mathbf{1} / \mathbf{2}} \\
{[\mathbf{n s}]^{, \boldsymbol{d}}}\end{array}$ & $\begin{array}{c}\text { PLQY } \\
{[\%]^{b}}\end{array}$ & $\begin{array}{c}\lambda_{e m}^{\max } \\
{[\mathbf{n m}]^{d}}\end{array}$ & $\begin{array}{c}\boldsymbol{\tau}_{\text {ave }} \\
{[\mathbf{n s}]^{d, e}}\end{array}$ & $\begin{array}{c}\text { PLQY } \\
{[\%]^{b}}\end{array}$ & $\begin{array}{c}\lambda_{e m}^{\max } \\
{[\mathbf{n m}]}\end{array}$ & $\begin{array}{c}\text { PLQY } \\
{[\%]}\end{array}$ \\
\hline $\mathbf{1}$ & 644 & 222 & 7.7 & 630 & 277 & 8.6 & 645 & 11.0 \\
\hline $\mathbf{2}$ & 636 & 329 & 14.0 & 630 & 305 & 16.0 & 642 & 17.6 \\
\hline $\mathbf{3}$ & 645 & 183 & 6.5 & 638 & 214 & 8.5 & 651 & 9.7 \\
\hline $\mathbf{4}$ & 636 & 275 & 11.0 & 625 & 287 & 10.0 & 626 & 12.5 \\
\hline $\mathbf{5}$ & 652 & $169^{e}$ & 4.1 & 648 & 185 & 3.1 & 658 & 5.8 \\
\hline $\mathbf{6}$ & 636 & $166^{e}$ & 5.9 & 616 & 236 & 9.7 & 625 & 12.3 \\
\hline $\mathbf{7}$ & 686 & 126 & 3.6 & 656 & 565 & 17.0 & 693 & 6.7 \\
\hline
\end{tabular}

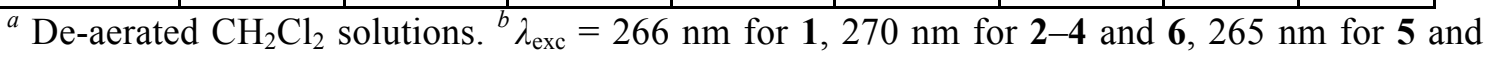
$259 \mathrm{~nm}$ for $7 .{ }^{c}$ Measured under an atmosphere of argon. ${ }^{d} \lambda_{\mathrm{exc}}=280 \mathrm{~nm} .{ }^{e} \tau_{\text {ave }}$ (biexponential fits were used for the excited state lifetime determination). ${ }^{f} \lambda_{\mathrm{exc}}=320 \mathrm{~nm}$. 


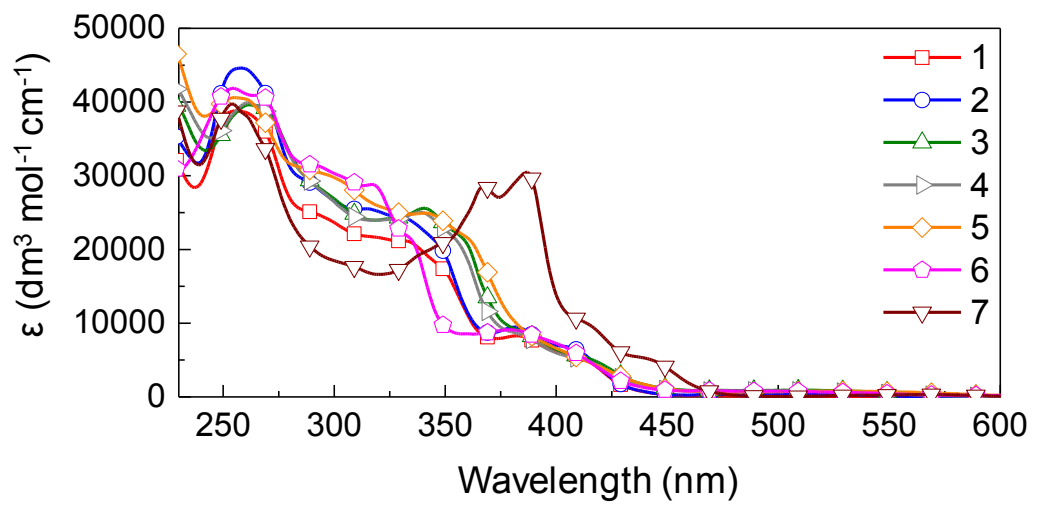

Figure 4. UV-Vis absorption spectra in $\mathrm{CH}_{2} \mathrm{Cl}_{2}$ solution $\left(1.0 \times 10^{-5} \mathrm{~mol} \mathrm{dm}^{-3}\right)$ of complexes 17.

Excitation of $\mathrm{CH}_{2} \mathrm{Cl}_{2}$ solutions of complexes 1-7 gives the photoluminescence spectra shown in Figure 5 with photophysical data summarized in Table 2. Emission maxima lie in the red to deep-red region, ranging from 636 to $686 \mathrm{~nm}$. For all complexes, the shapes and positions of the emission bands are independent of the excitation wavelength. Introduction of ligand $\mathbf{L} \mathbf{1}$ leads to a $49 \mathrm{~nm}$ red-shift of the emission maximum in $\mathrm{CH}_{2} \mathrm{Cl}_{2}$ when compared to the archetype complex $\left[\operatorname{Ir}(\mathrm{ppy})_{2}(\mathrm{bpy})\right]\left[\mathrm{PF}_{6}\right](595 \mathrm{~nm}$, bpy $=2,2$ '-bipyridine $) .{ }^{58}$ This red-shift can be explained by the electron-deficient nature of the benzothiazole moiety, leading to stabilization of the LUMO and as a consequence a smaller energy gap. Replacing the pyridine ring of $\mathbf{L 1}$ by another benzothiazole unit (ligand L7) leads to a further $42 \mathrm{~nm}$ bathochromic shift of the emission maximum in 7. Substituting $\mathbf{L 1}$ with a further benzothiazole group (ligand L5) does not have the same effect as L7; the pendant benzothiazole ring in 5 red-shifts the emission maximum by only $8 \mathrm{~nm}$. Coordination of the benzothiazole to the iridium center is therefore crucial for a substantial bathochromic shift. With the exception of 7 , the emission maxima of all complexes in this series are found in a small $16 \mathrm{~nm}$ range between 636 and $652 \mathrm{~nm}$, corresponding to red emission. Introduction of a pendant phenyl (3) or benzothiazole ring (5) exerts a negligible influence on the luminescence maximum. An $8 \mathrm{~nm}$ blue-shift of the emission band is observed upon tert-butyl substitution on the pyridyl ring in complexes 2 and $\mathbf{4}$. The same effect is observed by changing the benzothiazole to a benzoxazole unit in the ancillary ligand (complex 6). The majority of complexes in this series show broad, unstructured emission profiles, indicating a large charge transfer character of the emissive state. Some vibrational structure is observed in the emission bands of complexes 2 and $\mathbf{6}$, suggesting that the ${ }^{3} \mathrm{LC}$ contribution is more pronounced in the emissive state of these two complexes. Photoluminescence quantum yields in solution are generally low $(<10 \%)$ within this series of complexes (Table 2), but unexceptional for red emitters. A tert-butyl substituent on the ancillary 
ligand in 2 and 4 leads to slightly higher PLQYs of 14.0 and $11.0 \%$, respectively. Lifetimes were determined using biexponential fits in the case of compounds 5 and $\mathbf{6}$; data are given in Table 2.

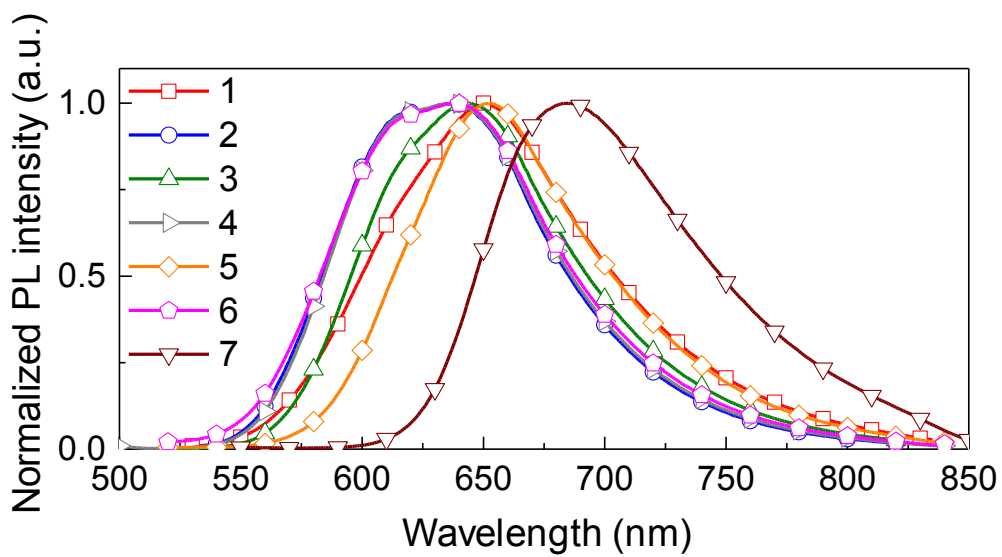

Figure 5. Photoluminescence spectra in $\mathrm{CH}_{2} \mathrm{Cl}_{2}$ solution $\left(1.0 \times 10^{-5} \mathrm{~mol} \mathrm{dm}^{-3}\right)$ of complexes 17. $\lambda_{\mathrm{exc}}=430 \mathrm{~nm}$ for $\mathbf{1}-\mathbf{6}$ and $445 \mathrm{~nm}$ for 7 .

Emission spectra of powder samples are depicted in Figure 6; emission maxima, quantum yields, and excited-state lifetimes are summarized in Table 2. All complexes exhibit a blue-shift in the range 4-30 nm on going from $\mathrm{CH}_{2} \mathrm{Cl}_{2}$ solution to the solid state (powder). The largest shift is seen for compound 7; this is also the only complex in this series which has a structured emission profile in the solid state. PLQYs vary from 3.1\% for complex 5 to $17.0 \%$ for complex 7. Biexponential fits were used for solid state decay curves of all complexes. Average lifetimes lie in the range 185-565 ns, with complex 7 exhibiting not only the highest quantum yield, but also the longest $\tau_{\text {ave }}$. Thin films of the complexes combined with $[\mathrm{Bmim}]\left[\mathrm{PF}_{6}\right]$ as ionic liquid (4:1 ratio) were spin-coated onto quartz substrates to determine their photophysical properties. For compound 2, 2 wt-\% poly(methyl methacrylate) (PMMA) was added to increase the quality of the film. The photoluminescence spectra of the different films are depicted in Figure 7 and the deduced emission maxima and quantum yields are reported in Table 2. Apart from complex 4, red-shifts in the emission maxima are observed for all complexes on going from powder samples to thin films. A pronounced red-shift of $37 \mathrm{~nm}$ is seen for complex 7, resulting in an emission maximum close to the near-infrared region $(693 \mathrm{~nm})$. All other complexes exhibit smaller bathochromic shifts ranging from 9 to $15 \mathrm{~nm}$. Interaction of the complexes with the ionic liquid in thin films apparently leads to a slight stabilization of the triplet emissive state and thus a smaller energy gap. The PLQY of the films of all but complex 7 are similar to the values obtained from the powder samples (Table 2). Only for complex 7, the PLQY is significantly lower in film (6.7\%) than for the powder sample (17\%). 


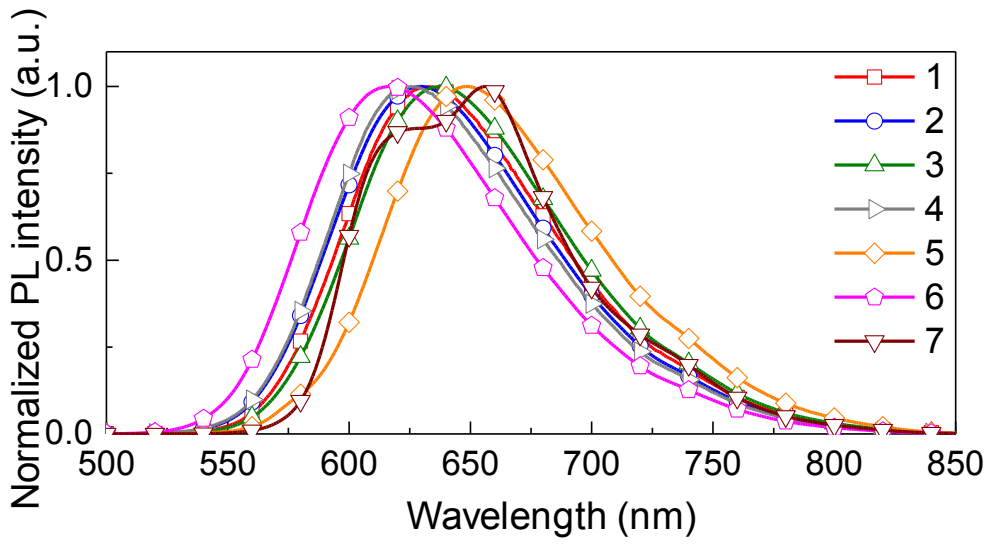

Figure 6. Solid-state photoluminescence spectra of powder samples of complexes 1-7. $\lambda_{\mathrm{exc}}=$ $280 \mathrm{~nm}$.

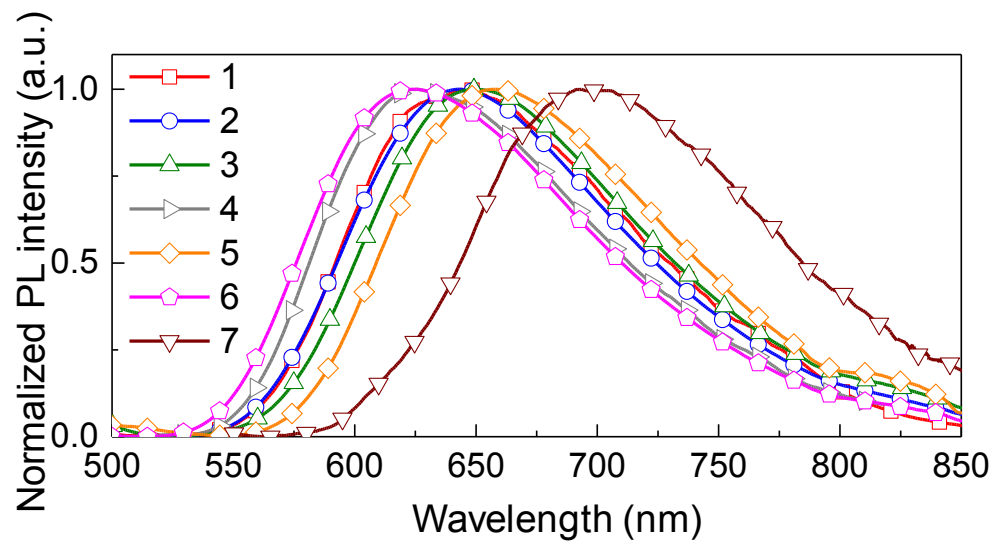

Figure 7. Thin-film photoluminescence spectra of complexes 1-7. $\lambda_{\mathrm{exc}}=320 \mathrm{~nm}$.

\section{Theoretical calculations}

To obtain a deeper knowledge of the electrochemical and photophysical properties of complexes 1-7, the molecular and electronic structures of the respective $\left[\operatorname{Ir}(\operatorname{ppy})_{2}\left(\mathrm{~N}^{\wedge} \mathrm{N}\right)\right]^{+}$ cations, in both ground and excited electronic states, were investigated by means of density functional theory (DFT) calculations at the B3LYP/(6-31G**+LANL2DZ) level in presence of the solvent $\left(\mathrm{CH}_{2} \mathrm{Cl}_{2}\right)$.

The minimum-energy geometries calculated for the $\left[\operatorname{Ir}(\mathrm{ppy})_{2}\left(\mathrm{~N}^{\wedge} \mathrm{N}\right)\right]^{+}$cations in their electronic ground state $\left(\mathrm{S}_{0}\right)$ reproduce the near-octahedral coordination of the Ir metal and are in good agreement with the X-ray diffraction data presented above for 1, 6, and 7. For these complexes, the $\mathrm{N}^{\wedge} \mathrm{N}$ ligands are predicted to be mainly planar (angle between ring planes $=2.7$, 1.9 and $3.8^{\circ}$, respectively). For $\mathbf{3}, \mathbf{4}$, and $\mathbf{5}$, the ancillary ligand deviates more from planarity (angle between ring planes $=14.6,16.0$, and $14.3^{\circ}$ respectively) to accommodate the pendant 
phenyl or benzothiazolyl groups. These groups give rise to a face-to-face $\pi$-stacking with the phenyl group of the adjacent ppy ${ }^{-}$ligand, similar to the intracation stacking observed for $\left[\operatorname{Ir}(\text { ppy })_{2}(\mathrm{Phbpy})\right]^{+}(\mathrm{Phbpy}=6$-phenyl-2,2'-bipyridine $)$ and $\left[\operatorname{Ir}(\mathrm{ppy})_{2}(\mathrm{Naphbpy})\right]^{+}(\mathrm{Naphbpy}=6-$ (2-naphthyl)-2,2'-bipyridine) in previous studies. ${ }^{55,59}$ The centroid-centroid distance between the stacked rings is $3.78,3.80$, and $3.74 \AA$ for $\mathbf{3}, \mathbf{4}$, and $\mathbf{5}$, respectively.

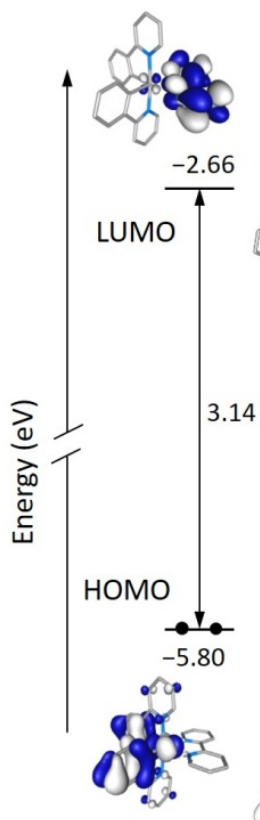

$\left[\operatorname{Ir}(\text { ppy })_{2}(\text { bpy })\right]^{+}$
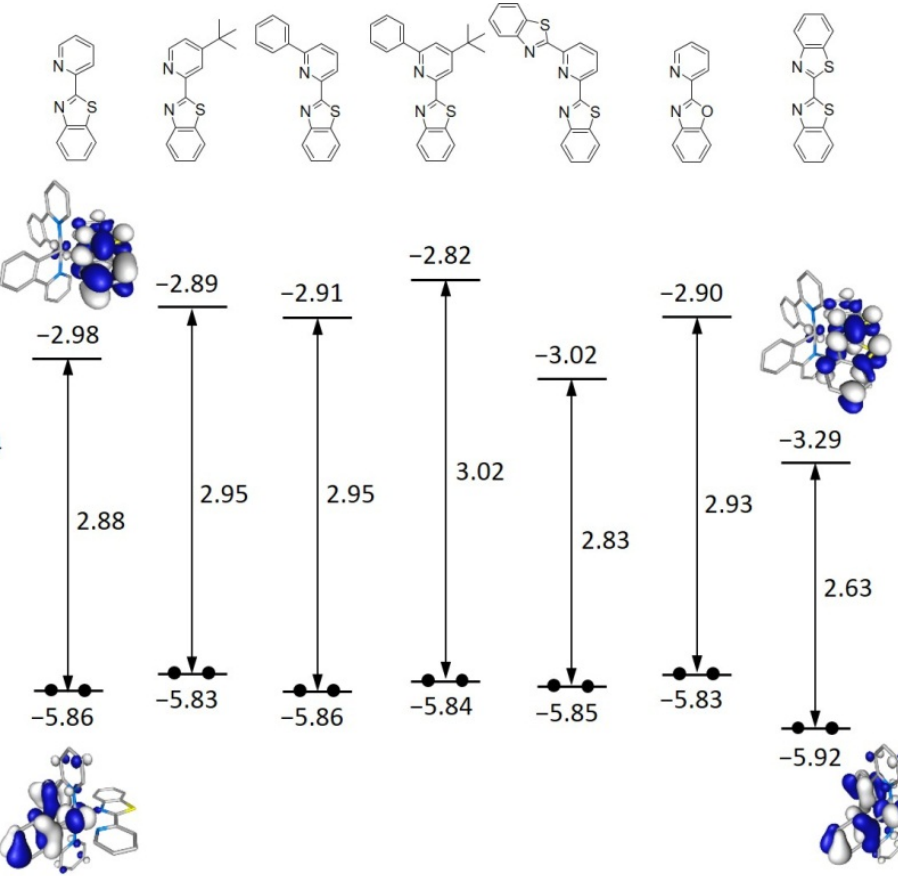

1

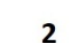

4

Figure 8. Schematic representation comparing the energies calculated for the frontier molecular orbitals of the archetype complex $\left[\operatorname{Ir}(\mathrm{ppy})_{2}(\mathrm{bpy})\right]^{+}$and of complexes 1-7. Isovalue contours ( \pm 0.03 a.u.) of the HOMO and LUMO are included for $\left[\operatorname{Ir}(\text { ppy })_{2}(\text { bpy })\right]^{+}, \mathbf{1}$, and 7 . Hydrogen atoms are omitted for clarity. The chemical structure of the $\mathrm{N}^{\wedge} \mathrm{N}$ ligands is shown in the upper part of the Figure.

Figure 8 compares the energies calculated for the frontier molecular orbitals of complexes 1-7 with those obtained for the archetypal $\left[\operatorname{Ir}(\mathrm{ppy})_{2}(\mathrm{bpy})\right]^{+}$complex. The contour plots of the highest-occupied (HOMO) and lowest-unoccupied (LUMO) molecular orbitals show the same topology for all the complexes and only those computed for $\left[\operatorname{Ir}(\mathrm{ppy})_{2}(\mathrm{bpy})\right]^{+}, \mathbf{1}$, and $\mathbf{7}$ are depicted in Figure 8 as representative examples. As usually found for $\left[\operatorname{Ir}\left(\mathrm{C}^{\wedge} \mathrm{N}\right)_{2}\left(\mathrm{~N}^{\wedge} \mathrm{N}\right)\right]^{+}$ complexes, the HOMO spreads over the iridium center and the phenyl rings of the ppy ${ }^{-}$ligands, whereas the LUMO is located over the $\mathrm{N}^{\wedge} \mathrm{N}$ ligand. The energy of the HOMO remains almost constant along the series 1-6 ( -5.83 to $-5.86 \mathrm{eV})$, and close to that of the archetypal complex ($5.80 \mathrm{eV}$ ). This is an expected behavior because all the complexes bear the same $\mathrm{C}^{\wedge} \mathrm{N}$ ligands and the structural differences are related to the ancillary ligand from which the HOMO has no 
contribution. Hence, the energy of the HOMO is only indirectly affected as in complex 7, that features a slightly lower HOMO energy $(-5.92 \mathrm{eV})$ due to electron-deficient nature of ligand L7. The theoretical predictions are in good agreement with the very similar oxidation potentials measured for complexes 1-4 and 6, and the higher value recorded for 7. No significant difference is expected for complex $\mathbf{5}$, for which the measured potential is irreversible.

Regarding the LUMO, its energy undergoes significant changes due to the different structure of the ancillary ligand (see Figure 8). The substitution of the bpy ligand in the reference $\left[\operatorname{Ir}(\mathrm{ppy})_{2}(\mathrm{bpy})\right]^{+}$complex by the btzpy ligand incorporating the benzothiazole unit in $\mathbf{1}$ stabilizes the LUMO by $0.33 \mathrm{eV}$, passing from $-2.66 \mathrm{eV}$ in $\left[\operatorname{Ir}(\text { ppy })_{2}(\text { bpy })\right]^{+}$to $-2.98 \mathrm{eV}$ in $\mathbf{1}$. The attachment of additional tert-butyl and phenyl groups to the pyridine moiety of btzpy leads to accumulative destabilizations of the LUMO of $\mathbf{2}(-2.89 \mathrm{eV}), \mathbf{3}(-2.91 \mathrm{eV})$, and $\mathbf{4}(-2.82 \mathrm{eV})$ compared with 1. Replacing benzothiazole by benzoxazole has a similar small destabilization effect in the LUMO of $6(-2.90 \mathrm{eV})$. In contrast, the attachment of a second benzothiazole unit produces a small stabilization of the LUMO of $5(-3.02 \mathrm{eV})$. The greatest effect is found for complex $7(-3.29 \mathrm{eV})$, for which the pyridine ring is substituted by a second electron-deficient benzothiazole unit, and the LUMO is stabilized by $0.31 \mathrm{eV}$. The theoretical trends fully support the reduction potentials measured experimentally (Table 1), which present close values for $\mathbf{2 ,} \mathbf{3}$, 4, and $\mathbf{6}$ (around $-1.60 \mathrm{~V})$, slightly more negative than $\mathbf{1}(-1.55 \mathrm{~V})$, and less negative values for $5(-1.47 \mathrm{~V})$ and especially for $7(-1.27 \mathrm{~V})$.

The HOMO-LUMO energy gaps calculated for 1-7 are in all cases smaller than that computed for the archetype complex $(3.14 \mathrm{eV})$. The largest gap in the family is predicted for complex 4 (3.02 eV), it decreases for complexes 2, 3, and 6, that show gaps around $2.95 \mathrm{eV}$, and in passing to $\mathbf{1}(2.88 \mathrm{eV})$ and $\mathbf{6}(2.83 \mathrm{eV})$, and the smallest gap is predicted for complex 7 (2.63 $\mathrm{eV}$ ). If emission comes from a triplet excited state originating in the HOMO $\rightarrow$ LUMO excitation, these results justify, in a first approach, the gradual shift to the red experimentally observed for the emission of complexes 1-6, and especially for 7, when compared with $\left[\operatorname{Ir}(\text { ppy })_{2}(\text { bpy })\right]^{+}$(Table 2).

To verify the nature of the emitting state, time-dependent DFT (TD-DFT) calculations of the lowest-energy triplet states were performed for the cations of complexes 1-7 at the optimized geometry of $\mathrm{S}_{0}$. Table $\mathrm{S} 2$ in the Supporting Information compiles the vertical excitation energies and the electronic description computed for the first three triplet excited states. Results for complexes 1-7 mostly present the same pattern. The lowest-lying triplet state $\left(\mathrm{T}_{1}\right)$ is mainly described by the HOMO $\rightarrow$ LUMO excitation and has a ${ }^{3} \mathrm{MLCT} /{ }^{3} \mathrm{LLCT}$ nature. The second lowest state $\left(\mathrm{T}_{2}\right)$, which also has a ${ }^{3} \mathrm{MLCT} /{ }^{3} \mathrm{LLCT}$ nature, appears $0.3-0.4 \mathrm{eV}$ higher in energy than $\mathrm{T}_{1}$ and presents some ${ }^{3} \mathrm{LC}$ character (13-22\%) due to excitations centered on the ancillary ligand. The third state $\left(\mathrm{T}_{3}\right)$ mainly implies the $\mathrm{C}^{\wedge} \mathrm{N}$ ligands $\left({ }^{3} \mathrm{LC}\right.$ nature) with some 
contribution from the metal and is computed more than $0.5 \mathrm{eV}$ above $\mathrm{T}_{1}$. The energy differences between these states point to the HOMO $\rightarrow \mathrm{LUMO}^{3} \mathrm{MLCT} /{ }^{3} \mathrm{LLCT}$ state as the emissive triplet state for complexes 1-7.

To further confirm the nature of the emitting triplet, the geometry of the lowest-lying triplet state was optimized using the spin-unrestricted UB3LYP approach. Figure 9a summarizes the adiabatic energy difference between $\mathrm{S}_{0}$ and $\mathrm{T}_{1}(\Delta E)$ and the emission energy $\left(E_{\mathrm{em}}\right)$ estimated as the vertical energy difference between $\mathrm{T}_{1}$ and $\mathrm{S}_{0}$ at the optimized minimum-energy geometry of $\mathrm{T}_{1}$. Fig. $9 \mathrm{~b}$ shows the unpaired-electron spin-density distributions computed for the fully relaxed $\mathrm{T}_{1}$ states of complexes 1 and 7 as representative examples. All the complexes exhibit similar spin density plots spreading the ppy-Ir environment and the $\mathrm{N}^{\wedge} \mathrm{N}$ ligand $\left(\operatorname{Ir} \sim 0.5 \mathrm{e}, \mathrm{C}^{\wedge} \mathrm{N}\right.$ ligands $\sim 0.5 \mathrm{e}, \mathrm{N}^{\wedge} \mathrm{N}$ ligand $\left.\sim 1.0 \mathrm{e}\right)$ that perfectly match the topology of the HOMO $\rightarrow$ LUMO excitation indicating an electron transfer from the $\operatorname{Ir}(\mathrm{ppy})_{2}$ moiety to the ancillary ligand. This supports the ${ }^{3} \mathrm{MLCT} /{ }^{3} \mathrm{LLCT}$ nature predicted for the emitting state by the TD-DFT calculations and agrees with the broad and unstructured bands observed in the photoluminescence spectra. The DFT values predicted for $E_{\text {em }}$ are in the range 1.58-1.79 eV (Figure 9a) underestimating the experimental emission energies by $0.1-0.2 \mathrm{eV}$. They correctly reproduce the main experimental trends featuring similar emission energies for complexes $1-4$ and 6 , a slightly redder emission for $\mathbf{5}$, and a deeper red emission for 7 .

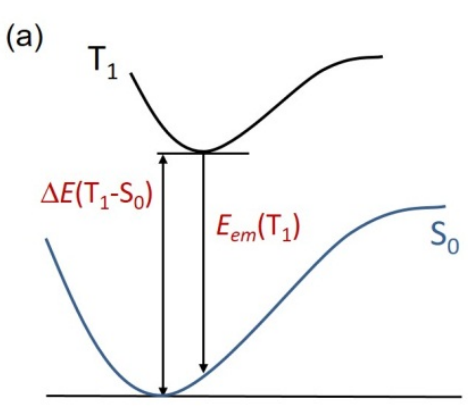

\begin{tabular}{c|cc} 
Complex & $\Delta E(\mathrm{eV})$ & $E_{\mathrm{em}}(\mathrm{eV})$ \\
\hline $\mathbf{1}$ & 2.06 & 1.79 \\
$\mathbf{2}$ & 2.08 & 1.82 \\
$\mathbf{3}$ & 2.07 & 1.78 \\
$\mathbf{4}$ & 2.10 & 1.80 \\
$\mathbf{5}$ & 1.98 & 1.70 \\
$\mathbf{6}$ & 2.11 & 1.84 \\
$\mathbf{7}$ & 1.81 & 1.58
\end{tabular}

(b)

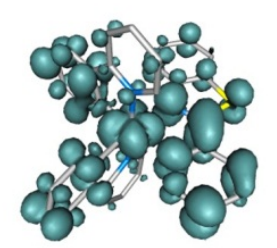

1

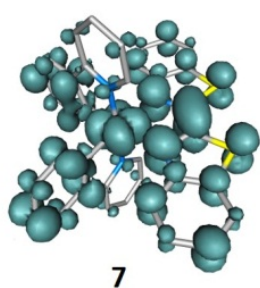

7

Figure 9. a) Schematic energy diagram showing the adiabatic energy difference $(\Delta E)$ between the $\mathrm{S}_{0}$ and $\mathrm{T}_{1}$ states and the emission energy $\left(E_{\text {em }}\right)$ from $\mathrm{T}_{1}$ calculated for complexes 1-7. b) Unpaired-electron spin-density contours (0.002 a.u.) calculated for fully relaxed $\mathrm{T}_{1}$ states of complexes 1 and 7. 
TD-DFT calculations of the lowest-lying singlet excited states were also performed to disentangle the different features observed in the absorption spectra (Figure 4). For complex 7 , two relatively intense $S_{0} \rightarrow S_{n}$ electronic transitions are computed at 362 and $373 \mathrm{~nm}$, with oscillator strengths of 0.10 and 0.59 respectively. These transitions originate from $\pi \rightarrow \pi^{*}$ excitations centered over the 2,2'-bibenzo $[d]$ thiazole (L7) ligand. The corresponding transitions for complexes 1-6 are found at higher energies and show lower intensities (for 1: 328 and 335 $\mathrm{nm}$, with oscillator strengths of 0.30 and 0.15 , respectively). These differences explain the more intense absorption bands recorded experimentally for 7 at wavelengths higher than $360 \mathrm{~nm}$, which are not observed for the other complexes (Figure 4).

\section{Light-emitting electrochemical cells (LECs)}

Simple two-layer LECs were prepared to investigate the electroluminescent properties of complexes 1-7. For clarity, LECs fabricated using complexes 1-7 will be referred as LECs 1-7. LEC structure is as follows, ITO/PEDOT:PSS/complex(1-7):IL/Al layout, as explained in the experimental section. The IL was added to reduce the turn-on time $\left(t_{\mathrm{on}}\right)$ defined as the time to reach a luminance of $100 \mathrm{~cd} \mathrm{~m}^{-2} .^{60}$

LECs are dynamic devices and are characterized in a different way than OLEDs. In particular, the frequently used luminance and current density versus voltage scans used in OLEDs cannot be used since, due to the slow ionic motion occurring in LECs, they operate in a different manor depending on the scan speeds. Therefore, LECs are generally studied under either fixed voltage or fixed current density over time. As mentioned earlier, our group has shown the benefits of operating the device under pulsed-current driving. ${ }^{14,61}$ In this study, LECs 1-7 were evaluated using a pulsed-current with an average current density of $100 \mathrm{~A} \cdot \mathrm{m}^{-2}$, consisting of a block wave at a $1000 \mathrm{~Hz}$ frequency with a duty cycle of $50 \%$. Using the pulsed driving mode LEC 7 did not produce any electroluminescence. This is most likely related to the poorer film quality of complex 7 resulting from its low solubility. Owing to the poor film quality, the distance between the anode and the cathode is not uniform over the device area which can lead to higher leakage current. A very high current density was indeed observed when operating LEC 7 under a constant-voltage of $4 \mathrm{~V}$, corroborating our hypothesis of high leakage currents (Figure S2).

The electroluminescence (EL) spectra of LECs 1-7 are shown in Figure 10. All the LECs 1-7 emit in the red region The Commision Internationale de l'Eclairage (CIE) coordinates for LECs 1-6 were determined from the electroluminescence spectra and are collected in Table 3. The EL spectra for LECs 1, 2, 3 and 5 are similar to the PL spectra indicative of the similar 
excited states being involved in the light emission process. LEC 4 show a red-shift of $22 \mathrm{~nm}$ $\left(\lambda_{\mathrm{em}}{ }^{\max } \mathrm{EL}=648 \mathrm{~nm}\right)$ and LEC 6 has a blue-shift of $27 \mathrm{~nm}\left(\lambda_{\mathrm{em}}{ }^{\max } \mathrm{EL}=598 \mathrm{~nm}\right)$, for reasons, currently not yet understood. These electroluminescence spectra are very interesting as up to now only few pure red LECs have been reported. ${ }^{25,62-64}$

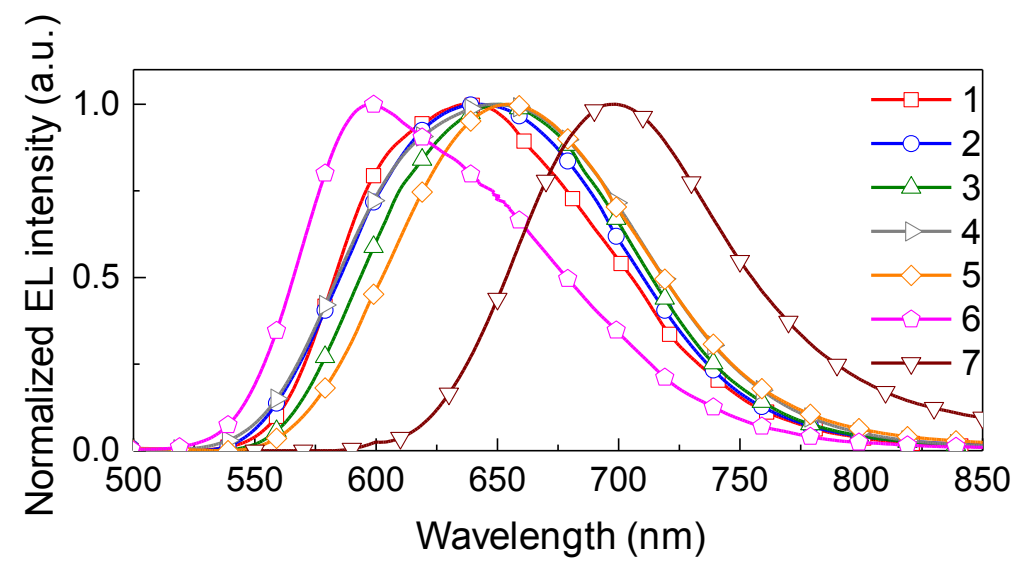

Figure 10. Electroluminescence spectra of LECs 1-7 driven either at an average pulsed-current density of $100 \mathrm{~A} \cdot \mathrm{m}^{-2}(1000 \mathrm{~Hz}, 50 \%$ duty cycle, block wave) for 1-6 or constant-voltage for 7 .

The evolution of the luminance versus time for LECs $\mathbf{1}-\mathbf{6}$ driven at $100 \mathrm{~A} \cdot \mathrm{m}^{-2}$ average pulsed-current density is shown in Figure 11 and the performance key parameters are given in Table 3. LECs 1-6 present the typical behavior under pulsed-current mode operation. The luminance rises while the voltage drops due to the growth of the $\mathrm{p}$ - and $\mathrm{n}$-doped regions in the active layer. ${ }^{14}$ Once the maximum luminance is attained, the luminance starts to decrease and the operating average voltage remains constant with values between 2.00 and $2.58 \mathrm{~V}$. 

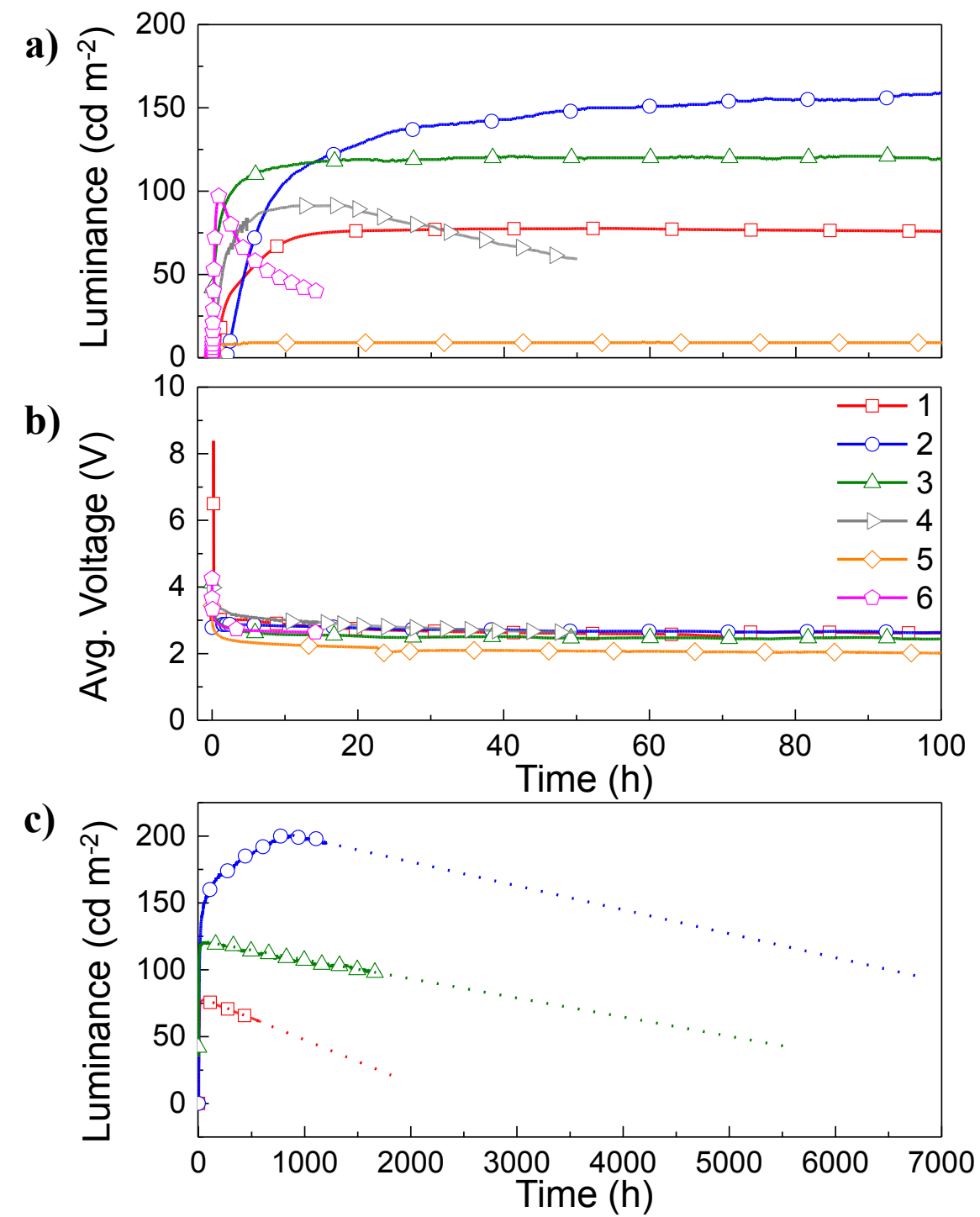

Figure 11. Luminance (a, c) and average voltage (b) versus time of LECs 1-6 operated under an average pulsed-current density of $100 \mathrm{~A} \cdot \mathrm{m}^{-2}(1000 \mathrm{~Hz}, 50 \%$ duty cycle, block wave). Panel c shows the extrapolation of the luminance to half the initial value for LECs 1-3.

LEC 1 presents a maximum luminance of $77 \mathrm{~cd} \cdot \mathrm{m}^{-2}$ after $54 \mathrm{~h}$ under operation, which implies that the ionic movement in this system is slow. The device lifetime, expressed by the time to reach one-half of the maximum luminance $\left(t_{1 / 2}\right)$, was estimated by extrapolating the luminance curve leading to a value higher than $1000 \mathrm{~h}$. Moreover, the LECs 2, and 3 actually show a higher maximum luminance $\left(200\right.$ and $\left.119 \mathrm{~cd} \cdot \mathrm{m}^{-2}\right)$ and further enhanced device stability than LEC 1 (Table 3). The best device of the series (LEC 2) has a $t_{1 / 2}$ in excess of $6000 \mathrm{~h}$ under the operating conditions (average pulsed-current density of $100 \mathrm{~A} \cdot \mathrm{m}^{-2}$ ). An extended timedependent luminance graph for LEC 2 up to $1200 \mathrm{~h}$ under operation is depicted in Figure S3. Its 
turn-on $\left(t_{\mathrm{on}}\right)$ defined as time to reach $50 \mathrm{~cd} \cdot \mathrm{m}^{-2}$ rises similar to LEC 1 ( 4.6 and $4.3 \mathrm{~h}$ for LEC $\mathbf{1}$ and 2 respectively), yet its luminance continues to increase over a long time indicating that optimum charge injection and charge balance are only slowly obtained, which could indicate that this slow ionic motion leads to a very slow doping growing over time becoming beneficial for the device lifetime. ${ }^{65,66}$ The higher luminance obtained for LEC $\mathbf{2}$ is due to the higher PLQY measured for complex 2 (17.6\%) compared with complex 1 (11\%). LEC 3 incorporating the complex with the pendant phenyl group attached to the $\mathrm{N}^{\wedge} \mathrm{N}$ ligand also shows a higher luminance $\left(\operatorname{lum}_{\max }=119 \mathrm{~cd} \cdot \mathrm{m}^{-2}\right.$ at $\left.63 \mathrm{~h}\right)$ and a longer lifetime $(>4500 \mathrm{~h})$ than complex 1 ( $>$ $1000 \mathrm{~h}$ ). When increasing the size of the substituents beyond that of complex $\mathbf{3}$ as in $\mathbf{4}$ and $\mathbf{5}$, the corresponding LECs have a significantly reduced stability, they now decay on a timescale of tens of hours. The replacement of the benzothiazole unit (LEC 1) by a benzoxazole (LEC $\mathbf{6}$ ) maintains the luminance $\left(\operatorname{Lum}_{\max }=77\right.$ and $97 \mathrm{~cd} \cdot \mathrm{m}^{-2}$, respectively), yet produces a detrimental effect in terms of stability $\left(t_{1 / 2}>1000\right.$ and $150 \mathrm{~h}$, respectively). In general, the time to reach the maximum luminance $\left(t_{\max }\right)$ and $t_{\text {on }}$ for LECs 4-6 is almost four times faster than for LECs 1-3, which support the hypothesis that the device lifetime is mainly affected by the growth of the doped zones, which increases the quenching of excitons. LEC 7, as mentioned above, emits in the near infrared and is not included in Figure 11 because it did not work under pulsed driving operation. The response of LEC 7 under constant-voltage operation is shown in Figure S5. Conclusions are difficult to draw due to the high current density caused probably by the poor film formation, and higher-solubility complexes would be needed to evaluate this type of complexes more carefully.

Table 3. Performance parameters and electroluminescence data obtained for LECs 1-6 operated under a pulsed-current of $100 \mathrm{~A} \cdot \mathrm{m}^{-2}(1000 \mathrm{~Hz}, 50 \%$ duty cycle, block wave).

\begin{tabular}{|c|c|c|c|c|c|c|c|c|c|}
\hline LEC & $\begin{array}{l}\operatorname{Lum}_{\max }{ }^{a} \\
/ \mathrm{cd} \cdot \mathrm{m}^{-2}\end{array}$ & $\begin{array}{l}t_{\mathrm{on}}{ }^{b} \\
/ \mathrm{h}\end{array}$ & $\begin{array}{c}t_{\max }{ }^{c} \\
/ \mathrm{h}\end{array}$ & $\begin{array}{l}t_{1 / 2}^{d} \\
/ \mathrm{h}\end{array}$ & $\begin{array}{c}\text { Efficacy }_{\max }^{e} \\
/ \mathrm{cd} \cdot \mathrm{A}^{-1}\end{array}$ & $\begin{array}{c}\mathrm{PE}_{\max }{ }^{f} \\
/ \mathrm{lm} \cdot \mathrm{W}^{-1}\end{array}$ & $\begin{array}{c}\mathrm{EQE}_{\max }{ }^{g} \\
/ \%\end{array}$ & $\begin{array}{c}\lambda_{\mathrm{em}}^{\max } \mathrm{EL} \\
/ \mathrm{nm}\end{array}$ & $\mathrm{CIE}^{h}$ \\
\hline 1 & 77 & 4.6 & 54 & $>1000^{*}$ & 0.75 & 0.47 & 0.70 & 636 & $\begin{array}{c}0.6289 \\
0.3674\end{array}$ \\
\hline 2 & 200 & 4.3 & 870 & $>6000^{*}$ & 2.02 & 1.22 & 2.00 & 642 & $\begin{array}{l}0.6297 \\
0.3663\end{array}$ \\
\hline 3 & 119 & 0.2 & 63 & $>4500^{*}$ & 1.22 & 0.77 & 1.49 & 651 & $\begin{array}{c}0.6436, \\
0.3524\end{array}$ \\
\hline 4 & 91 & 1.3 & 18 & $63^{*}$ & 1.01 & 0.51 & 1.04 & 648 & $\begin{array}{c}0.6219 \\
0.3748\end{array}$ \\
\hline 5 & 9 & - & 4.8 & $>150^{*}$ & 0.09 & 0.06 & 0.14 & 655 & $\begin{array}{c}0.6476, \\
0.3393\end{array}$ \\
\hline 6 & 97 & 0.2 & 0.84 & 9 & 0.97 & 0.54 & 0.55 & 598 & $\begin{array}{c}0.5852 \text {, } \\
0.4109\end{array}$ \\
\hline
\end{tabular}

${ }^{a}$ Maximum luminance reached. ${ }^{b}$ Time to reach $50 \mathrm{~cd} \cdot \mathrm{m}^{-2}$ luminance. ${ }^{c}$ Time to reach the maximum luminance. ${ }^{d}$ Time to reach one-half of the maximum luminance. ${ }^{e}$ Maximum efficacy 
reached. ${ }^{f}$ Maximum power efficiency reached. ${ }^{g}$ Maximum external quantum efficiency reached. ${ }^{h}$ The Commission Internationale de l'Eclairage (CIE) colour coordinates. *Extrapolated values.

The current efficiency of LEC 1 is around $0.75 \mathrm{~cd} \cdot \mathrm{A}^{-1}$ and is stable over time. The stability is a result of the stable luminance resulting from the complex and the pulsed-current driving approach. The efficiency is not very high in part due to the emission wavelength, which is only in part visible to the human eye. LECs $\mathbf{2}$ and $\mathbf{3}$ are slightly better, as can be observed from their higher luminance values (Table 3 ), with efficacies of 2.02 and $1.22 \mathrm{~cd} \cdot \mathrm{A}^{-1}$, respectively.

In view of the deep-red emission wavelength, it is better to express the efficiency as the external quantum efficiency $(\mathrm{EQE})$ defined as:

$$
\mathrm{EQE}=b \varphi / 2 n^{2}
$$

where $b$ is the recombination efficiency (equal to 1 for two ohmic contacts), $\varphi$ is the fraction of excitons that decay radiatively, and $n$ is the refractive index of the glass substrate and is equal to 1.5 (the factor $1 / 2 n^{2}$ accounts for the coupling of light out of the device). As the Ir(III)-based complexes can efficiently harvest both singlet and triplet excitons, $\varphi$ should resemble the PL efficiency. Hence, the efficiency of the device is mainly determined by the PLQY of the iTMC emitter. The maximum EQE that can be obtained with a PLQY of $11 \%$ without special outcoupling structures is roughly $2.4 \%$.

Experimentally, this value is not observed, instead a maximum EQE of $0.70 \%$ for LEC 1 was obtained. However, due to the higher luminance achieved for LECs $\mathbf{2}$ and $\mathbf{3}$, the maximum EQE values for LECs 2 and 3 were 2.00 and 1.49\%, respectively. Several examples of redemitting LECs have been reported under constant-voltage operation, ${ }^{8,11,67,68}$ leading to champion peak EQEs of $9.51 \%$ with a limited $t_{1 / 2}$ of $8.2 \mathrm{~h} .{ }^{11}$ As commented before, the best way to attain stable devices is pulsed-current driving and, to the best of our knowledge, the best device lifetime for red-emitting LECs have been reported under pulsed-current ${ }^{69-71}$ or constantcurrent $^{72,73}$ operation with a maximum lifetime of $110 \mathrm{~h}$. Hence, the characteristics described here for LECs 1-3 show stabilities ranging from 10 to 60 times longer than those reported previously. These values are exceptional and are only comparable to very few orange emitting LECs operated under the same driving conditions. ${ }^{19}$ The performance of the stable red LECs is limited by the moderate luminance and the rather slow response, which is dependent on the applied current and generally linked to the device stability (higher current density leads to lower device lifetime). For this reason, we further investigate how the device stability is affected by increasing the current density. 


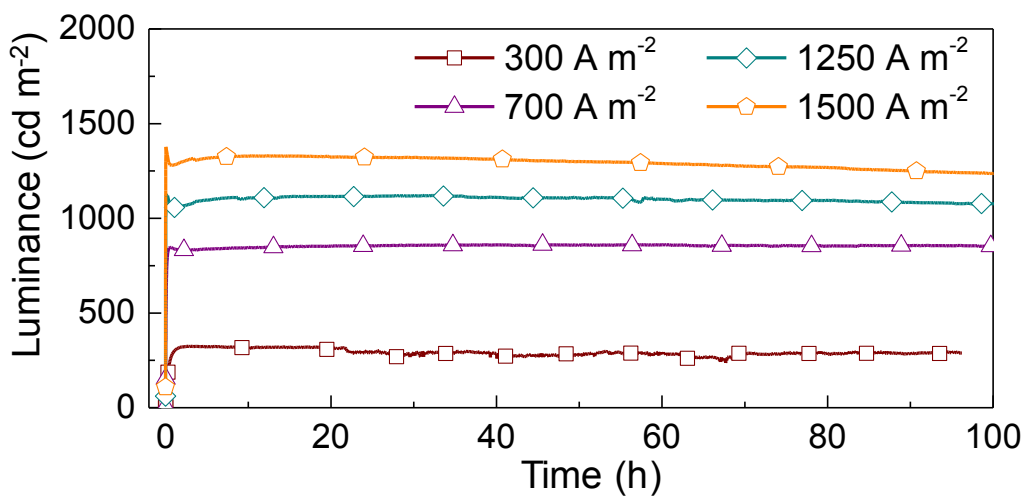

Figure 12. Time-dependent luminance of LEC 1 operated under different pulsed-current densities from 300 to $1500 \mathrm{~A} \cdot \mathrm{m}^{-2}$.

To do this, a good performing complex obtained in sufficient large quantities is needed to prepare a number of devices to be operated under increasing average current densities. Complex 1 was selected for this more in-depth analysis due to its simplest chemical structure. The luminance versus time measured for LEC 1 devices operated using pulsed-current densities (block wave, $1000 \mathrm{~Hz}$, and $50 \%$ duty cycle) of $300,700,1250$, and $1500 \mathrm{~A} \cdot \mathrm{m}^{-2}$ are depicted in Figure 12. The luminance decay is always very slow and, surprisingly, it does not depend very strongly on the applied current density. As mentioned before, this is remarkable as in electroluminescent devices a strong dependency of the lifetime on the current density is normally observed. There is virtually no luminance decay over the first $100 \mathrm{~h}$ (Figure 12) when driven under the pulsed conditions at average current densities of 300 and $700 \mathrm{~A} \cdot \mathrm{m}^{-2}$, and only a moderate decrease of approximately $10 \%$ is observed when the average current density is set at 1250 and $1500 \mathrm{~A} \cdot \mathrm{m}^{-2}$ after $100 \mathrm{~h}$. The luminance decay of the LEC 1 driven at $700 \mathrm{~A} \cdot \mathrm{m}^{-2}$ was followed for a longer time $(450 \mathrm{~h})$ resulting in a decay of only $15 \%$ (Figure S4). The quasi steady-state luminance that is reached by each device increases linearly in the range from 100 to $700 \mathrm{~A} \cdot \mathrm{m}^{-2}$. For clarity, the luminance curve for the lower current density $\left(100 \mathrm{~A} \cdot \mathrm{m}^{-2}\right)$ is not depicted in Figure 12. At higher applied current densities than $700 \mathrm{~A} \cdot \mathrm{m}^{-2}$, the luminance values still increase but less than linearly. This linear dependence has been previously reported in LEC devices operated in pulse mode at very low current densities. However, this linearity is not usually present at high current densities. ${ }^{56}$ This implies that there is little exciton-exciton or exciton-polaron quenching up to high current densities of $700 \mathrm{~A} \cdot \mathrm{m}^{-2}$, as this would lead to a sublinear increase, and that the luminance intensity can be tuned by the current density applied. The time to reach the maximum luminance (Figure S5a) is also affected by the applied average current density and interestingly, the time to reach $100 \mathrm{~cd} \cdot \mathrm{m}^{-2}$ is substantially reduced to the second scale, from $500 \mathrm{~s}$ at $300 \mathrm{~A} \cdot \mathrm{m}^{-2}$ to $5 \mathrm{~s}$ at $1500 \mathrm{~A} \cdot \mathrm{m}^{-2}$ (Figure 13). For lower current 
densities it takes longer to reach the maximum luminance. This is related to the voltage that is applied, which is lower for lower applied current densities (FigureS5b). Once the maximum luminance is reached, the operating voltage rapidly drops to values in between 2.5 and $2.9 \mathrm{~V}$, depending on the set current density. Herein it is demonstrated the possibility of tuning the luminance levels, fast response with almost no lost in device stability, which is step forward in the demand for red light applications.

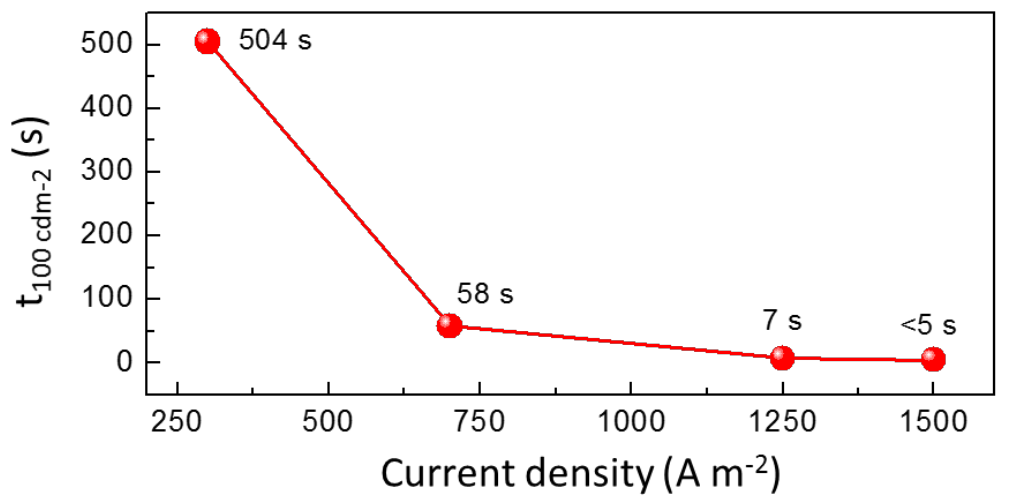

Figure 13. Time to reach $100 \mathrm{~cd} \cdot \mathrm{m}^{-2}\left(t_{100 \mathrm{~cd} \mathrm{~m}-2}\right)$ versus applied current densities (pulsed current, $1000 \mathrm{~Hz}, 50 \%$ duty cycle, block wave) for LEC $\mathbf{1}$.

\section{CONCLUSIONS}

In conclusion, a series of ionic iridium(III) complexes using two 2-phenylpyridinate cyclometalating ligands and one 2-(pyridin-2-yl)benzo $[d]$ thiazole based ancillary $\left(\mathrm{N}^{\wedge} \mathrm{N}\right)$ ligand have been designed, prepared, and fully characterized. These complexes are efficient red emitters and have been used to prepare light-emitting electrochemical cells. The effects of modifying the chemical structure of the 2-(pyridin-2-yl)benzo[d]thiazole ligand and its substitution by 2 -(pyridin-2-yl)benzo[ $[d]$ oxazole and 2,2 -bibenzo $[d]$ thiazole units on the photoluminescence and device performance are carefully studied. Density functional calculations clearly show that these chemical changes only affect the LUMO level leading to important reductions of the HOMO-LUMO energy gap compared to the archetypal $\left[\operatorname{Ir}(\text { ppy })_{2}(\right.$ bpy $\left.)\right]$ complex. The emissive triplet state corresponds in all cases to the $\mathrm{HOMO} \rightarrow$ LUMO ${ }^{3} \mathrm{MLCT} /{ }^{3} \mathrm{LLCT}$ state. Strikingly, stable red-emitting LECs are obtained. In particular, LECs using the complexes incorporating 2-(pyridin-2-yl)benzo[d]thiazole, 2-(4-(tertbutyl)pyridin-2-yl)benzo[ $d]$ thiazole, and 2-(6-phenylpyridin-2-yl)benzo[ $d]$ thiazole as ancillary ligands exhibit lifetimes in excess of 1000, 6000, and $4000 \mathrm{~h}$, respectively. This demonstrates that these ligands are very interesting to be further explore in both ionic and neutral iridiumbased phosphorescent complexes. 
Supporting Information. Synthetic details, crystallographic, cyclic voltammetry and phololuminescence data and TD-DFT results, and electroluminescent data.

\section{ACKNOWLEDGEMENTS}

This work has been supported by the Spanish Ministry of Economy and Competitiveness (MINECO) (MAT2014-55200, CTQ2015-71154-P, and Unidad de Excelencia María de Maeztu MDM-2015-0538), the Generalitat Valenciana (PROMETEO/2016/135), European Feder funds (CTQ2015-71154-P), the Swiss National Science Foundation (Grant number 200020_144500), the European Research Council (Advanced Grant 267816 LiLo) and the University of Basel. C. M. thanks the MINECO for a predoctoral contract. M.G.L.P. thanks the Generalitat Valenciana for her Santiago Grisolia Fellowship.

\section{REFERENCES}

(1) Pei, Q.; Yu, G.; Zhang, C.; Yang, Y.; Heeger, A. J. Science 1995, 269, 1086.

(2) Lee, J. K.; Yoo, D. S.; Handy, E. S.; Rubner, M. F. Appl. Phys. Lett. 1996, 69, 1686.

(3) Gao, F. G.; Bard, A. J. J. Am. Chem. Soc. 2000, 122, 7426.

(4) Kalyuzhny, G.; Buda, M.; McNeill, J.; Barbara, P.; Bard, A. J. J. Am. Chem. Soc. 2003, 125, 6272.

(5) Rudmann, H.; Shimada, S.; Rubner, M. F. J. Appl. Phys. 2003, 94, 115.

(6) Slinker, J.; Bernards, D.; Houston, P. L.; Abruna, H. D.; Bernhard, S.; Malliaras, G. G. Chem. Commun. 2003, 2392.

(7) Slinker, J. D.; Gorodetsky, A. A.; Lowry, M. S.; Wang, J.; Parker, S.; Rohl, R.; Bernhard, S.; Malliaras, G. G. J. Am. Chem. Soc. 2004, 126, 2763.

(8) Tamayo, A. B.; Garon, S.; Sajoto, T.; Djurovich, P. I.; Tsyba, I. M.; Bau, R.; Thompson, M. E. Inorg. Chem. 2005, 44, 8723.

(9) Wågberg, T.; Hania, P. R.; Robinson, N. D.; Shin, J.-H.; Matyba, P.; Edman, L. Adv. Mater. 2008, 20, 1744.

(10) Tang, S.; Pan, J.; Buchholz, H. A.; Edman, L. J. Am. Chem. Soc. 2013, 135, 3647.

(11) Zhang, J.; Zhou, L.; Al-Attar, H. A.; Shao, K.; Wang, L.; Zhu, D.; Su, Z.; Bryce, M. R.; Monkman, A. P. Adv. Funct. Mater. 2013, 23, 4667.

(12) Meier, S. B.; Tordera, D.; Pertegás, A.; Roldán-Carmona, C.; Ortí, E.; Bolink, H. J. Mater. Today 
2014, 17, 217.

(13) Sun, Q.; Li, Y.; Pei, Q. J. Disp. Technol. 2007, 3, 211.

(14) Tordera, D.; Meier, S.; Lenes, M.; Costa, R. D.; Ortí, E.; Sarfert, W.; Bolink, H. J. Adv. Mater. 2012, 24, 897.

(15) Hu, T.; He, L.; Duan, L.; Qiu, Y. J. Mater. Chem. 2012, 22, 4206.

(16) Zhang, Z.; Guo, K.; Li, Y.; Li, X.; Guan, G.; Li, H.; Luo, Y.; Zhao, F.; Zhang, Q.; Wei, B.; Pei, Q.; Peng, H. Nat. Photonics 2015, 9, 233.

(17) Henwood, A. F.; Zysman-Colman, E. Top. Curr. Chem. 2016, 374, 36.

(18) Slinker, J. D.; Gorodetsky, A. A.; Lowry, M. S.; Wang, J.; Parker, S.; Rohl, R.; Bernhard, S.; Malliaras, G. G. J. Am. Chem. Soc. 2004, 126, 2763.

(19) Tordera, D.; Pertegas, A.; Shavaleev, N. M.; Scopelliti, R.; Orti, E.; Bolink, H. J.; Baranoff, E.; Gratzel, M.; Nazeeruddin, M. K. J. Mater. Chem. 2012, 22, 19264.

(20) Tordera, D.; Frey, J.; Vonlanthen, D.; Constable, E.; Pertegás, A.; Ortí, E.; Bolink, H. J.; Baranoff, E.; Nazeeruddin, M. K. Adv. Energy Mater. 2013, 3, 1338.

(21) AlTal, F.; Gao, J. Org. Electron. 2015, 18, 1.

(22) Lin, K.-Y.; Bastatas, L. D.; Suhr, K. J.; Moore, M. D.; Holliday, B. J.; Minary-Jolandan, M.; Slinker, J. D. ACS Appl. Mater. Interfaces 2016, 8, 16776.

(23) Suhr, K. J.; Bastatas, L. D.; Shen, Y.; Mitchell, L. A.; Holliday, B. J.; Slinker, J. D. ACS Appl. Mater. Interfaces 2016, 8, 8888 .

(24) Bandiello, E.; Sessolo, M.; Bolink, H. J. J. Mater. Chem. C 2016, 4, 10781.

(25) Rodriguez-Redondo, J. L.; Costa, R. D.; Orti, E.; Sastre-Santos, A.; Bolink, H. J.; Fernandez-Lazaro, F. Dalton Trans. 2009, 9787.

(26) Costa, R. D.; Ortí, E.; Bolink, H. J.; Graber, S.; Schaffner, S.; Neuburger, M.; Housecroft, C. E.; Constable, E. C. Adv. Funct. Mater. 2009, 19, 3456.

(27) Hu, T.; Duan, L.; Qiao, J.; He, L.; Zhang, D.; Wang, L.; Qiu, Y. Synth. Met. 2013, 163, 33.

(28) Lo, K. K.-W.; Li, C.-K.; Lau, J. S.-Y. Organometallics 2005, 24, 4594.

(29) Yuan, Y.-J.; Yu, Z.-T.; Chen, X.-Y.; Zhang, J.-Y.; Zou, Z.-G. Chem. - Eur. J. 2011, 17, 12891.

(30) Lo, K. K.-W.; Leung, S.-K.; Pan, C.-Y. Inorg. Chim. Acta 2012, 380, 343.

(31) Choudhary, C. K.; Choudhary, R. K.; Mishra, L. K. Complexes of rhodium(III), palladium(II) and platinum(II) with 2-(2'-pyridyl)benzthiazole; Indian Chemical Society: Calcutta, INDE, 2002.

(32) Richardson, C.; Keene, F. R.; Steel, P. J. Aust. J. Chem. 2008, 61, 183. 
(33) Gärtner, F.; Cozzula, D.; Losse, S.; Boddien, A.; Anilkumar, G.; Junge, H.; Schulz, T.; Marquet, N.; Spannenberg, A.; Gladiali, S.; Beller, M. Chem. - Eur. J. 2011, 17, 6998.

(34) Bruker Analytical X-ray Systems, I., 2006, APEX2, version 2 User Manual, M86-E01078, Madison, WI.

(35) Sheldrick, G. Acta Crystallogr., Sect. A: Found. Crystallogr. 2008, 64, 112.

(36) Betteridge, P. W.; Carruthers, J. R.; Cooper, R. I.; Prout, K.; Watkin, D. J. J. Appl. Crystallogr. 2003, 36, 1487.

(37) Frisch, M. J.; Trucks, G. W.; Schlegel, H. B.; Scuseria, G. E.; Robb, M. A.; Cheeseman, J. R.; Scalmani, G.; Barone, V.; Mennucci, B.; Petersson, G. A.; Nakatsuji, H.; Caricato, M.; Li, X.; Hratchian, H. P.; Izmaylov, A. F.; Bloino, J.; Zheng, G.; Sonnenberg, J. L.; Hada, M.; Ehara, M.; Toyota, K.; Fukuda, R.; Hasegawa, J.; Ishida, M.; Nakajima, T.; Honda, Y.; Kitao, O.; Nakai, H.; Vreven, T.; Montgomery Jr., J. A.; Peralta, J. E.; Ogliaro, F.; Bearpark, M. J.; Heyd, J.; Brothers, E. N.; Kudin, K. N.; Staroverov, V. N.; Kobayashi, R.; Normand, J.; Raghavachari, K.; Rendell, A. P.; Burant, J. C.; Iyengar, S. S.; Tomasi, J.; Cossi, M.; Rega, N.; Millam, N. J.; Klene, M.; Knox, J. E.; Cross, J. B.; Bakken, V.; Adamo, C.; Jaramillo, J.; Gomperts, R.; Stratmann, R. E.; Yazyev, O.; Austin, A. J.; Cammi, R.; Pomelli, C.; Ochterski, J. W.; Martin, R. L.; Morokuma, K.; Zakrzewski, V. G.; Voth, G. A.; Salvador, P.; Dannenberg, J. J.; Dapprich, S.; Daniels, A. D.; Farkas, Ö.; Foresman, J. B.; Ortiz, J. V.; Cioslowski, J.; Fox, D. J.; Gaussian 09, Revision D.01, Gaussian, Inc.: Wallingford, CT., 2009.

(38) Lee, C.; Yang, W.; Parr, R. G. Phys. Rev. B 1988, 37, 785.

(39) Becke, A. D. J. Chem. Phys. 1993, 98, 5648.

(40) Francl, M. M.; Pietro, W. J.; Hehre, W. J.; Binkley, J. S.; Gordon, M. S.; DeFrees, D. J.; Pople, J. A. J. Chem. Phys. 1982, 77, 3654.

(41) Hay, P. J.; Wadt, W. R. J. Chem. Phys. 1985, 82, 299.

(42) Tomasi, J.; Persico, M. Chem. Rev. 1994, 94, 2027.

(43) Cramer, C. S.; Truhlar, D. G. Solvent Effects and Chemical Reactivity, Kluwer 1996, 1.

(44) Tomasi, J.; Mennucci, B.; Cammi, R. Chem. Rev. 2005, 105, 2999.

(45) Casida, M. E.; Jamorski, C.; Casida, K. C.; Salahub, D. R. J. Chem. Phys. 1998, 108, 4439.

(46) Jamorski, C.; Casida, M. E.; Salahub, D. R. J. Chem. Phys. 1996, 104, 5134.

(47) Petersilka, M.; Gossmann, U. J.; Gross, E. K. U. Phys. Rev. Lett. 1996, 76, 1212.

(48) Do, H.-Q.; Khan, R. M. K.; Daugulis, O. J. Am. Chem. Soc. 2008, 130, 15185.

(49) Carlson, L. J.; Welby, J.; Zebrowski, K. A.; Wilk, M. M.; Giroux, R.; Ciancio, N.; Tanski, J. M.; Bradley, A.; Tyler, L. A. Inorg. Chim. Acta 2011, 365, 159.

(50) Rai, C.; Braunwarth, J. B. J. Org. Chem. 1961, 26, 3434. 
(51) Vandromme, L.; Reißig, H.-U.; Gröper, S.; Rabe, J. P. Eur. J. Org. Chem. 2008, 12, 2049.

(52) Tordera, D.; Bünzli, A. M.; Pertegás, A.; Junquera-Hernández, J. M.; Constable, E. C.; Zampese, J. A.; Housecroft, C. E.; Ortí, E.; Bolink, H. J. Chem. Eur. J. 2013, 19, 8597.

(53) Neve, F.; Crispini, A.; Campagna, S.; Serroni, S. Inorg. Chem. 1999, 38, 2250.

(54) Costa, R. D.; Ortí, E.; Tordera, D.; Pertegás, A.; Bolink, H. J.; Graber, S.; Housecroft, C. E.; Sachno, L.; Neuburger, M.; Constable, E. C. Adv. Energy Mater. 2011, 1, 282.

(55) Schneider, G. E.; Bolink, H. J.; Constable, E. C.; Ertl, C. D.; Housecroft, C. E.; Pertegas, A.; Zampese, J. A.; Kanitz, A.; Kessler, F.; Meier, S. B. Dalton Trans. 2014, 43, 1961.

(56) Bunzli, A. M.; Constable, E. C.; Housecroft, C. E.; Prescimone, A.; Zampese, J. A.; Longo, G.; Gil-Escrig, L.; Pertegas, A.; Orti, E.; Bolink, H. J. Chem. Sci. 2015, 6, 2843.

(57) Spek, A. L. Acta Crystallogr., Sect. D: Biol. Crystallogr. 2009, 65, 148.

(58) Constable, E. C.; Neuburger, M.; Rösel, P.; Schneider, G. E.; Zampese, J. A.; Housecroft, C. E.; Monti, F.; Armaroli, N.; Costa, R. D.; Ortí, E. Inorg. Chem. 2013, 52, 885.

(59) Bolink, H. J.; Coronado, E.; Costa, R. D.; Ortí, E.; Sessolo, M.; Graber, S.; Doyle, K.; Neuburger, M.; Housecroft, C. E.; Constable, E. C. Adv. Mater. 2008, 20, 3910.

(60) Parker, S. T.; Slinker, J. D.; Lowry, M. S.; Cox, M. P.; Bernhard, S.; Malliaras, G. G. Chem. Mater. 2005, 17, 3187.

(61) Shavaleev, N. M.; Scopelliti, R.; Gratzel, M.; Nazeeruddin, M. K.; Pertegas, A.; RoldanCarmona, C.; Tordera, D.; Bolink, H. J. J. Mater. Chem. C 2013, 1, 2241.

(62) Bolink, H. J.; Coronado, E.; Costa, R. D.; Gaviña, P.; Ortí, E.; Tatay, S. Inorg. Chem. 2009, $48,3907$.

(63) Ho, C.-C.; Chen, H.-F.; Ho, Y.-C.; Liao, C.-T.; Su, H.-C.; Wong, K.-T. Phys. Chem. Chem. Phys. 2011, 13, 17729.

(64) Ross, D. A. W.; Scattergood, P. A.; Babaei, A.; Pertegas, A.; Bolink, H. J.; Elliott, P. I. P. Dalton Trans. 2016, 45, 7748.

(65) Meier, S. B.; Hartmann, D.; Tordera, D.; Bolink, H. J.; Winnacker, A.; Sarfert, W. Phys. Chem. Chem. Phys. 2012, 14, 10886.

(66) AlTal, F.; Gao, J. Org. Electron. 2015, 18, 1.

(67) He, L.; Qiao, J.; Duan, L.; Dong, G.; Zhang, D.; Wang, L.; Qiu, Y. Adv. Funct. Mater. 2009, 19, 2950.

(68) Xu, W.-J.; Liu, S.-J.; Ma, T.-C.; Zhao, Q.; Pertegas, A.; Tordera, D.; Bolink, H. J.; Ye, S.H.; Liu, X.-M.; Sun, S.; Huang, W. J. Mater. Chem. 2011, 21, 13999.

(69) Constable, E. C.; Housecroft, C. E.; Schneider, G. E.; Zampese, J. A.; Bolink, H. J.; Pertegas, A.; Roldan-Carmona, C. Dalton Trans. 2014, 43, 4653. 
(70) Weber, M. D.; Adam, M.; Tykwinski, R. R.; Costa, R. D. Adv. Funct. Mater. 2015, 25, 5066.

(71) Weber, M. D.; Wittmann, J. E.; Burger, A.; Malcıoğlu, O. B.; Segarra-Martí, J.; Hirsch, A.; Coto, P. B.; Bockstedte, M.; Costa, R. D. Adv. Funct. Mater. 2016, 26, 6737.

(72) Hasan, K.; Donato, L.; Shen, Y.; D. Slinker, J.; Zysman-Colman, E. Dalton Trans. 2014, $43,13672$.

(73) Suhr, K. J.; Bastatas, L. D.; Shen, Y.; Mitchell, L. A.; Frazier, G. A.; Taylor, D. W.; Slinker, J. D.; Holliday, B. J. Dalton Trans. 2016, 45, 17807. 


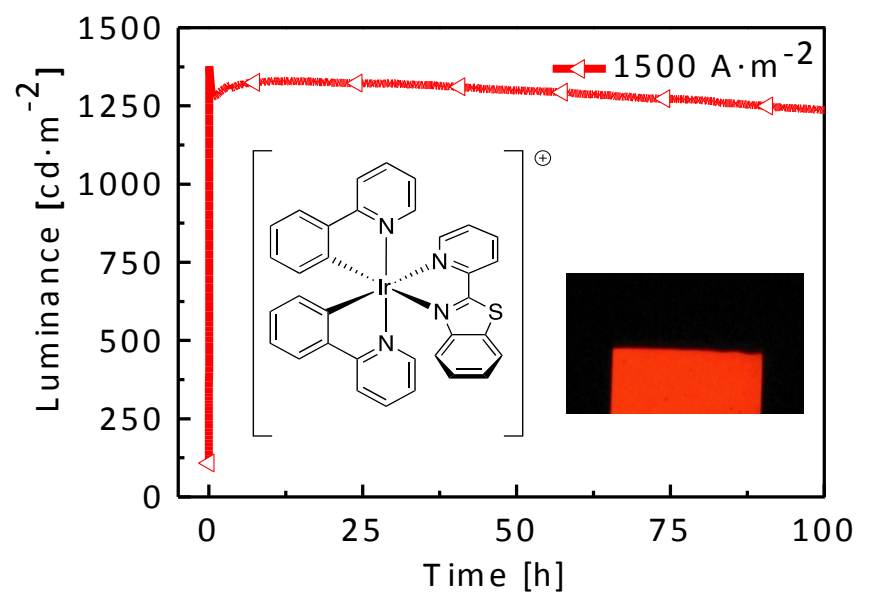

